\title{
Chitin-Binding Protein of Verticillium nonalfalfae Disguises Fungus from Plant Chitinases and Suppresses Chitin-Triggered Host Immunity
}

\author{
Helena Volk, ${ }^{1}$ Kristina Marton, ${ }^{1}$ Marko Flajšman, ${ }^{1}$ Sebastjan Radišek, ${ }^{2}$ Hui Tian, ${ }^{3}$ Ingo Hein,,${ }^{4,5}$ \\ Črtomir Podlipnik, ${ }^{6}$ Bart P. H. J. Thomma, ${ }^{3}$ Katarina Košmelj, ${ }^{1}$ Branka Javornik, ${ }^{1}$ and Sabina Berne ${ }^{1, \dagger}$ \\ ${ }^{1}$ Department of Agronomy, Biotechnical Faculty, University of Ljubljana, Jamnikarjeva 101, SI-1000 Ljubljana, Slovenia \\ ${ }^{2}$ Slovenian Institute of Hop Research and Brewing, Cesta Žalskega tabora 2, SI-3310 Žalec, Slovenia \\ ${ }^{3}$ Laboratory of Phytopathology, Wageningen University and Research, Droevendaalsesteeg 1, 6708 PB Wageningen, The \\ Netherlands \\ ${ }^{4}$ The James Hutton Institute (JHI), Invergowrie, Dundee DD2 5DA, Scotland, U.K. \\ ${ }^{5}$ The University of Dundee, School of Life Sciences, Division of Plant Sciences at the JHI, Invergowrie \\ ${ }^{6}$ Department of Chemistry and Biochemistry, Faculty of Chemistry and Chemical Technology, University of Ljubljana, Večna pot \\ 113, SI-1000 Ljubljana, Slovenia
}

Accepted 6 May 2019.

\begin{abstract}
During fungal infections, plant cells secrete chitinases, which digest chitin in the fungal cell walls. The recognition of released chitin oligomers via lysin motif (LysM)-containing immune host receptors results in the activation of defense signaling pathways. We report here that Verticillium nonalfalfae, a hemibiotrophic xylem-invading fungus, prevents these digestion and recognition processes by secreting a carbohydratebinding motif 18 (CBM18)-chitin-binding protein, VnaChtBP, which is transcriptionally activated specifically during the parasitic life stages. VnaChtBP is encoded by the Vna8.213 gene, which is highly conserved within the species, suggesting high evolutionary stability and importance for the fungal lifestyle. In a pathogenicity assay, however, Vna8.213 knockout mutants exhibited wilting symptoms similar to the wild-type fungus, suggesting that Vna8.213 activity is functionally redundant during fungal infection of hop. In a binding assay, recombinant VnaChtBP bound chitin and chitin oligomers in vitro with submicromolar affinity and protected fungal hyphae from degradation by plant chitinases. Moreover, the chitintriggered production of reactive oxygen species from hop suspension cells was abolished in the presence of VnaChtBP, indicating that VnaChtBP also acts as a suppressor of chitintriggered immunity. Using a yeast-two-hybrid assay, circular
\end{abstract}

Nucleotide sequence data is available under accession numbers MH325205 for VnaChtBP and MH325206 for VaChtBP.

${ }^{\dagger}$ Corresponding author: S. Berne; sabina.berne@bf.uni-1j.si

Funding: This research was supported by the Slovenian Research Agency (Javna Agencija za Raziskovalno Dejavnost RS) grants P4-0077 and J48220 and fellowship 342257. This work benefitted from interactions promoted by the COST Action European Cooperation in Science and Technology FA 1208.

*The $\boldsymbol{e}$-Xtra logo stands for "electronic extra" and indicates that two supplementary files, four supplementary figures, and three supplementary tables are published online.

The author(s) declare no conflict of interest.

๑) 2019 The American Phytopathological Society dichroism, homology modeling, and molecular docking, we demonstrated that VnaChtBP forms dimers in the absence of ligands and that this interaction is stabilized by the binding of chitin hexamers with a similar preference in the two binding sites. Our data suggest that, in addition to chitin-binding LysM (CBM50) and Avr4 (CBM14) fungal effectors, structurally unrelated CBM18 effectors have convergently evolved to prevent hydrolysis of the fungal cell wall against plant chitinases and to interfere with chitin-triggered host immunity.

Keywords: fungal effectors, fungus-plant interactions, mechanisms of pathogenicity

Plant defense against pathogenic organisms relies on innate immunity, which is triggered by recognition of pathogenderived or endogenous danger signals by plant receptors, described as pattern-triggered immunity (PTI) and effectortriggered immunity, respectively (Dodds and Rathjen 2010; Jones and Dangl 2006). PTI is activated by host cell surfacelocalized pattern recognition receptors (PRRs) sensing pathogen- and danger-associated molecular patterns (PAMPs and DAMPs, respectively) (Boller and Felix 2009; Böhm et al. 2014). PRRs, which are either receptor-like kinases (RLKs) or receptor-like proteins (RLPs) that function in conjunction with RLKs, sense PAMPs or DAMPs and transduce downstream signaling to trigger PTI responses. Early PTI responses include the rapid generation of reactive oxygen species (ROS), the activation of ion channels, and mitogen-activated protein kinases. In turn, this leads to the expression of defense related genes, leading to an accumulation of antimicrobial compounds such as enzymes, which damage pathogen structures, inhibitors of pathogen enzymes, and other antimicrobial molecules (Boller and Felix 2009; Dodds and Rathjen 2010; Macho and Zipfel 2014).

PAMPs, released during infection, are conserved molecular patterns characteristic of different pathogen classes (Ranf 2017). In fungi, chitin, in addition to $\beta$-glucan and xylanase, is a well-studied PAMP that activates the host defense response (Sánchez-Vallet et al. 2015). Chitin [a polymer of $\beta$-1,4-linked $\mathrm{N}$-acetylglucosamine $\left.(\mathrm{GlcNAc})_{n}\right]$, is a major and highly 
conserved component of fungal cell walls and can be degraded to chitin oligosaccharides by plant apoplastic chitinases (Punja and Zhang 1993; Pusztahelyi 2018). The generated chitin fragments are recognized by a chitin perception system and subsequently activate PTI (Sánchez-Vallet et al. 2015; Shibuya and Minami 2001; Shinya et al. 2015).

Major chitin-sensing PRRs, RLKs, and RLPs belonging to the lysin motif (LysM) domain family are well studied in Arabidopsis and rice (Gust et al. 2012; Ranf 2017). Arabidopsis LysM-RLK chitin elicitor receptor kinase 1 (AtCERK1) binds $\mathrm{N}$-acetylated chitin fragments with three LysM motifs and, through homodimer formation, mediates chitin-inducible plant defenses (Liu et al. 2012; Miya et al. 2007). Cao et al. (2014) later identified another LysM-RLK in Arabidopsis, AtLYK5, which binds chitin at a higher affinity than AtCERK1. The authors propose that AtLYK5 functions as the major chitin receptor, which recruits AtCERK1 to form a chitin-inducible receptor complex. In rice, two receptors are involved in chitintriggered immunity (Shimizu et al. 2010). LysM-RLP chitin elicitor binding protein (OsCEBiP) binds $\mathrm{N}$-acetylated chitin fragments, which initiates receptor homodimerization and further heterodimerization with OsCERK1. This heterotetramer formation triggers chitin-induced PTI (Hayafune et al. 2014).

To overcome chitin-triggered immunity, successful pathogens have evolved various strategies, including alteration of the composition and structure of cell walls, modification of carbohydrate chains, and secretion of effector proteins to prevent hydrolysis of the fungal cell wall or the release and recognition of chitin oligosaccharides (Sánchez-Vallet et al. 2015).

A well-described strategy of fungal cell wall protection against host chitinases is that of the tomato leaf mold fungus Cladosporium fulvum, which secretes chitin-binding protein Avr4 during infection. Avr4 effector binds with its carbohydrate-binding module (CBM) family 14 (CBM14) to the fungal cell wall chitin and, thus, shields fungal hyphae against degradation by chitinases (van den Burg et al. 2006; van Esse et al. 2007). There is evidence of a similar protection of cell wall chitin in a phylogenetically closely related species of the Dothideomycete fungi class harboring homologs of Avr4 (Stergiopoulos et al. 2010). Protection of fungal hyphae against hydrolysis by chitinases has also been shown for fungal effectors Mg1LysM and Mg3LysM of Zymoseptoria tritici (formerly Mycosphaerella graminicola) (Marshall et al. 2011) and Vd2LysM from Verticillium dahliae (Kombrink et al. 2017), one of the LysM fungal effectors (de Jonge and Thomma 2009) that are known to bind chitin oligomers via LysM domains or CBM family 50 (CBM50) (Akcapinar et al. 2015). The first LysM effector, Ecp6, was found in the tomato pathogen C. fulvum and its characterization provided evidence that Ecp6 specifically and with high affinity binds chitin oligosaccharides. This competition with receptors subsequently disrupts chitin recognition by host receptors and suppresses the chitintriggered immune response (Bolton et al. 2008; de Jonge et al. 2010; Sánchez-Vallet et al. 2013). Some fungal genomes contain several genes for LysM effectors and those highly expressed during infection have been characterized in fungal pathogens, including Z. tritici (Marshall et al. 2011), Magnaporthe oryzae (Mentlak et al. 2012), Colletotrichum higginsianum (Takahara et al. 2016), and V. dahliae (Kombrink et al. 2017). These studies demonstrate the involvement of LysM effectors in shielding fungal hyphae from chitinases, in blocking chitin-induced plant defense responses and in pathogen virulence, or in a combination of these effects.

The question arises of whether there are other molecules, systems, or complexes, apart from Avr4 (CBM14) and LysM (CBM50) effectors, which can interfere with plant chitin perception and activation of PTI. We have been studying the
V. nonalfalfae-hop (Humulus lupulus L.) pathosystem. In an early comparative transcriptomic study of compatible and incompatible interactions (Cregeen et al. 2015), an in-plantaexpressed $V$. nonalfalfae lectin gene was detected. Its relative expression increased in susceptible hop cultivar Celeia and decreased in resistant cultivar Wye Target over the time course of infection. A preliminary study showed that this $V$. nonalfalfae lectin contains putative CBM family 18 (CBM18) (Wright et al. 1991) domains. CBM18 is a chitin-binding domain involved in recognition of chitin oligomers and typically found in fungal and plant proteins in one or more copies (Lerner and Raikhel 1992). Here, we report on the characterization of $V$. nonalfalfae lectin with six CBM18 domains and show that it is a novel effector in plant fungal pathogens. VnaChtBP binds chitin, suppresses chitin-triggered production of ROS in hop, and protects hyphae of Trichoderma viride from hop chitinases in an in vitro protection assay.

\section{RESULTS}

\section{The majority of CBM18-containing proteins} of $V$. nonalfalfae are expressed in planta.

The Vna8.213 gene, encoding a putative pathogen CBM18containing chitin-binding protein (VnaChtBP), has previously been identified as a differentially expressed transcript during compatible and incompatible interactions of $V$. nonalfalfae and hop (Cregeen et al. 2015). Surveying the $V$. nonalfalfae genome, (Jakše et al. 2018) uncovered 10 additional genes that encode for proteins with at least one CBM18 module (Fig. 1). These genes were grouped into four categories according to their domain architecture: lectin-like proteins (Fig. 1A), chitinases (Fig. 1B), chitin deacetlyases (Fig. 1C), and xyloglucan endotransglucosylase (Fig. 1D). The size of these proteins ranged between 349 and 1,696 amino acids (Vna6.1 and Vnal.668, respectively) and they harbored between 1 and 10 CBM18 modules. Of these genes, 10 are differentially expressed in planta (Fig. 1E) (Marton et al. 2018) and 5 (Vna2.980, Vna6.6, Vna8.213, Vna9.506, and Vna9.510) were predicted to be classically secreted proteins with N-terminal signal peptides. Of the chitinases (Fig. 1B), transcripts of Vna3.655 and Vna9.506 were detected exclusively in susceptible hop, Vnal.668 transcripts were found expressed in the roots of both resistant (Wye Target) and susceptible (Celeia) hop varieties, and transcripts of Vna2.980 and Vna9.510 were barely detectable. Interestingly, only one chitin deacetylase gene (VnaUn.355) was expressed during infection, and it showed preferential induction in the roots of both hop varieties. Such an expression profile was also evident for transcripts of Vna6.6 belonging to xyloglucan endotransglucosylase. The highest expression was observed for Vna8.213 transcripts, in particular at the late stages of infection of susceptible hop. Interestingly, the Vnal.667 gene-encoding lectin-like protein, containing 10 CBM18 modules, was barely expressed in the roots of susceptible hop during the early infection stages.

In addition to chitinases (Fig. 1B), which contain the family 18 glycoside hydrolase domain, one CBM18, and two to three CBM50 chitin-binding modules known as LysM domains, another group of protein-like LysM effectors (de Jonge and Thomma 2009) is encoded in the $V$. nonalfalfae genome. Seven genes harboring one to six LysM domains were found, four of them with signal peptide and five of them showing expression in infected hops (Supplementary Fig. S1). The highest expression in planta was determined for Vna2.731, which is predicted to encode a $19.3-\mathrm{kDa}$ protein with one transmembrane domain and one LysM domain and shares $99 \%$ identity with the VDBG_03944 protein from $V$. alfalfae, VaMs.102. 
To confirm the expression patterns of Vna8.213 measured by RNA-Seq, detailed gene expression profiling of root and shoot samples from susceptible and resistant hop varieties was performed using real-time quantitative PCR (RT-qPCR) at 6, 12, and 18 days postinoculation (dpi) with $V$. nonalfalfae (Fig. 2).
Gene expression of Vna8.213, hereinafter designated VnaChtBP, increased with time, reaching the highest abundance in stems of susceptible hop at $18 \mathrm{dpi}$. The overall VnaChtBP expression in resistant hop was at a much lower level than in the susceptible variety and peaked at $12 \mathrm{dpi}$ in
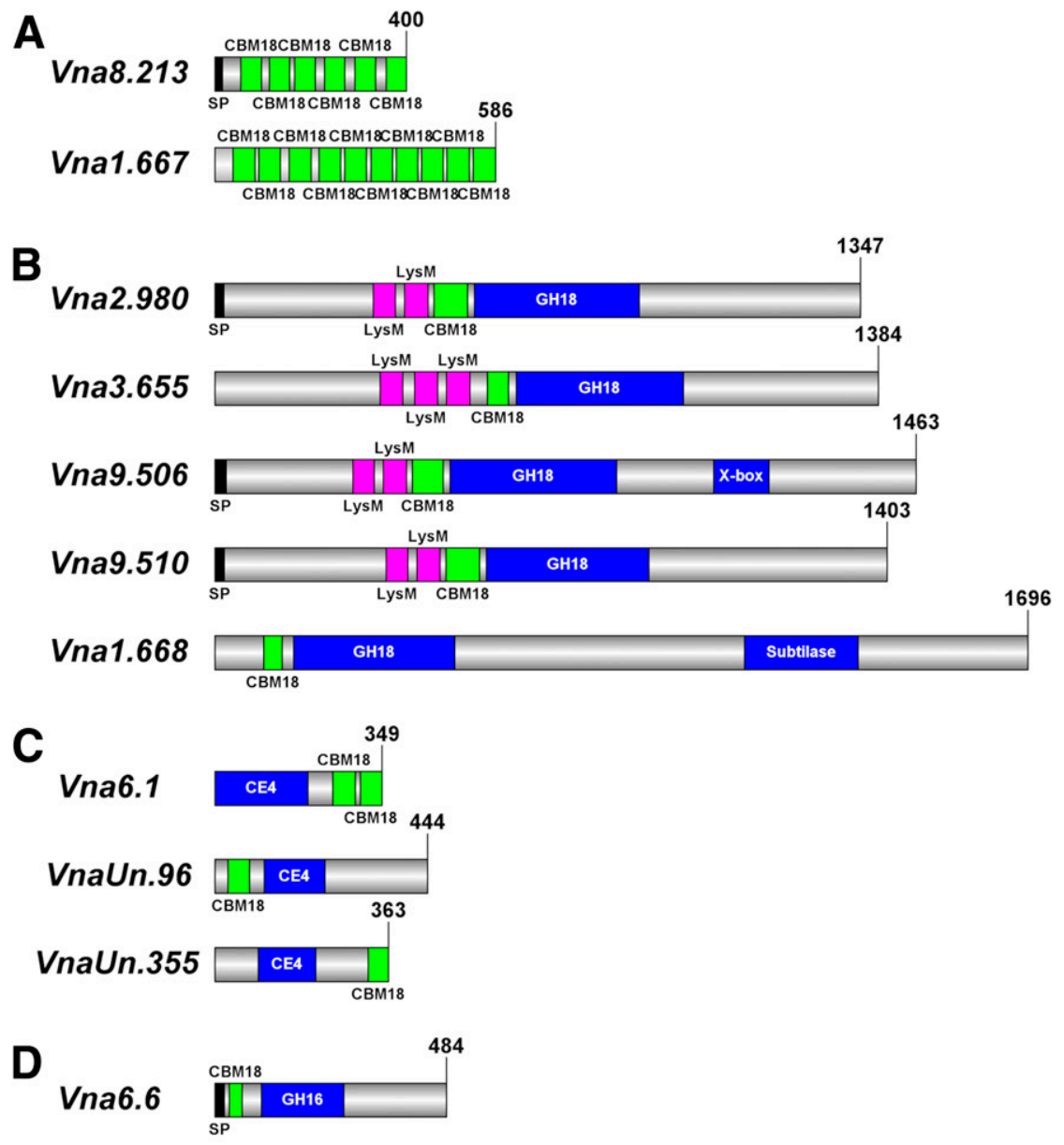

$\mathbf{E}$

Roots

Shoots

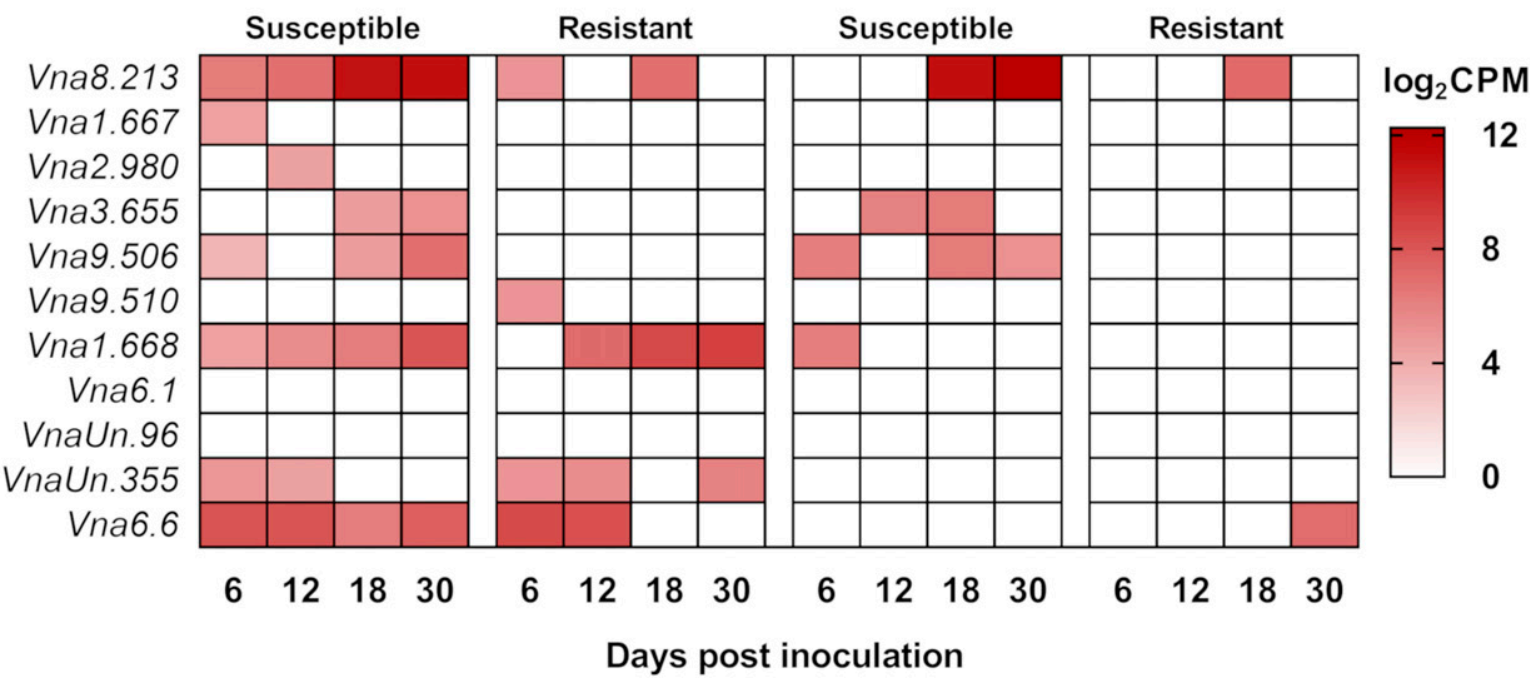

Fig. 1. A to D, Domain architecture and E, gene expression of carbohydrate-binding motif 18 (CBM18)-containing proteins identified in Verticillium nonalfalfae. Protein organization was determined by querying protein sequences against CATH-Gene3D (Dawson et al. 2017) using the FunFHMMer web server and presented by IBS software (Liu et al. 2015). Proteins were classified into four groups: lectin-like proteins (A), chitinases (B), chitin deacetlyases (C), and xyloglucan endotransglucosylase (D). Gene expression is presented as a heatmap of $\log _{2}$ counts per million (CPM) values determined by RNA sequencing of infected hop (Progar et al. 2017). 
stems. These results indicate that $V n a C h t B P$ expression is induced in planta and its transcript abundance in susceptible hop increases with the progression of fungal colonization.

\section{Sequence conservation suggests evolutionary stability of VnaChtBP.}

To investigate the presence and sequence variation of VnaChtBP in $28 \mathrm{~V}$. nonalfalfae isolates (Supplementary Table S1), PCR amplification and Sanger sequencing of cloned genes was performed. The VnaChtBP gene was present in all analyzed isolates and displayed no sequence polymorphisms. This suggests the evolutionary stability of the gene, as well as an important role in the fungal lifestyle.

Among all sequences deposited at NCBI, VnaChtBP shared the highest protein identity with a lectin from $V$. alfalfae $(97 \%$; alfalfa isolate VaMs.102), followed by $V$. dahliae lectin-B (80\%; lettuce isolate VdLs.17), two V. dahliae hypothetical proteins (Vd0004_g7043 and Vd0001_g7025; 80 and 79\%, strawberry isolates 12161 and 12158, respectively), and a hypothetical protein BN1708_012400 from V. longisporum (78\%; a rapeseed isolate VL1) (Supplementary Table S2). Additional homologs (Supplementary File S1) but with lower identity (48 to $39 \%$ ) were identified in fungi among classes Sordariomycetes $(n=40)$ and Dotideomycetes $(n=3)$, and in fungi Incertae sedis among classes Neocallimastigomycetes $(n=5)$ and Chytridiomycetes $(n=2)$.

Because of the high sequence similarity shared between VnaChtBP and $V$. alfalfae VaMs.102 lectin, PCR screening and Sanger sequencing of amplicons from four additional $V$. alfalfae isolates was carried out. As with VnaChtBP, no allelic polymorphisms were found among the sequences obtained and comparison of $V$. nonalfalfae and $V$. alfalfae gene sequences from these isolates also showed $97 \%$ sequence identity. Within the 36 single-nucleotide polymorphisms identified, only 13 resulted in amino acid substitutions (Supplementary File S2).

\section{VnaChtBP binds chitin in vitro and protects fungal hyphae against plant chitinases.}

$V$. nonalfalfae VnaChtBP is an intronless gene and predicted to encode for a cysteine-rich (12.5\%) apoplastic effector

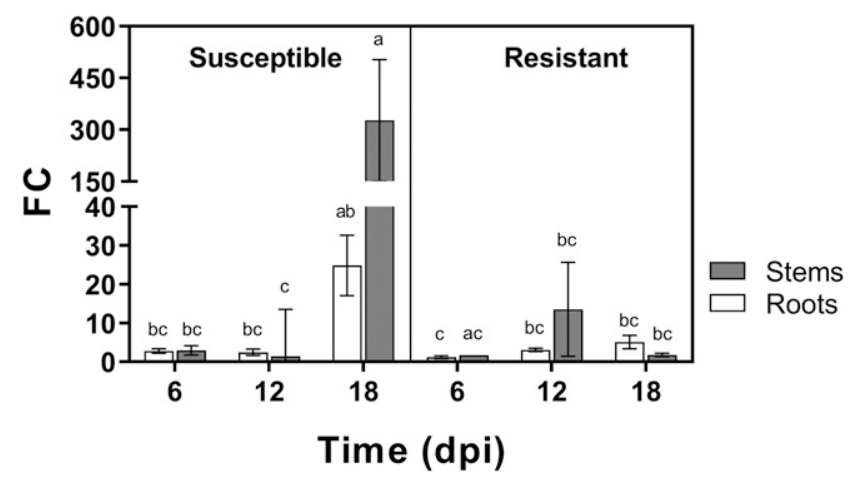

Fig. 2. VnaChtBP, a gene encoding the carbohydrate-binding motif 18 (CBM18) chitin-binding protein of Verticillium nonalfalfae, is highly expressed in stems of susceptible hop at the late stages of infection. The gene expression of VnaChtBP was quantified by real-time quantitative PCR using cDNA prepared from the roots and shoots of infected susceptible (Celeia) and resistant (Wye Target) hop plants $(n=5)$ at 6, 12, and 18 days postinoculation (dpi) and the expression levels were normalized relative to the expression of the gene in 1/2 liquid Czapek-Dox medium using topoisomerase (VnaUn.148) and splicing factor $3 \mathrm{a} 2$ (Vna8.801) as housekeeping genes (Marton et al. 2018). One-way analysis of variance with Tukey's post hoc test was performed to test for differences between the group means. $\mathrm{FC}=$ fold change.
(VnaChtBP) with 400 amino acids, including N-terminal signal peptide and six type 1 chitin-binding domains (ChtBD1; PF00187). This domain is classified in the CAZy database (Lombard et al. 2014) as CBM18 and consists of 30 to 43 residues rich in glycines and cysteines, which are organized in a conserved four-disulfide core (Andersen et al. 1993; Asensio et al. 2000; Wright et al. 1991). It is a common structural motif, with a consensus sequence X3CGX7CX4CCSX2GXCGX5CX3CX3CX2 (Prosite PS50941), is found in various plant and fungal defense proteins, and is involved in the recognition or binding of chitin subunits (Finn et al. 2014).

To confirm carbohydrate binding, Escherichia coli-produced and Ni-NTA affinity-purified recombinant VnaChtBP (Supplementary Fig. S2) was used in a sedimentation assay with various carbohydrates. VnaChtBP bound specifically to chitin polymer, in the form of chitin beads and crab shell chitin, but not to the plant cell wall polymers cellulose and xylan (Fig. 3). To examine the affinity of VnaChtBP binding to chitin in more detail, recombinant protein was immobilized to the CM5 sensor chip and the VnaChtBP interaction with chitin hexamer was analyzed using surface plasmon resonance (SPR) (Kastritis and Bonvin 2013). VnaChtBP revealed concentration-dependent binding of chitin hexamer (Fig. 4) with a dissociation constant of $0.78 \pm 0.58 \mu \mathrm{M}$, while no specific binding to other tested carbohydrates was detected (Supplementary Fig. S3). Because the chitin-binding affinity of the protein increases for longer chitin oligomers (Asensio et al. 2000), this value is comparable with other reported chitin oligomer binding affinities of fungal effectors but exceeds by one order of magnitude those reported for Arabidopsis chitin recognition receptors and hevein (Table 1), reported to protect fungal hyphae from plant chitinases (Marshall et al. 2011; van den Burg et al. 2004). To determine whether recombinant $\mathrm{VnaChtBP}$ can protect fungal cell walls against hydrolysis by plant chitinases, a cell protection assay adapted from Mentlak et al. (2012) was performed using germinating conidia of $T$. viride. Xylem sap extracted from $V$. nonalfalfae-infected hop (Flajšman et al. 2018) was used as a source of plant chitinases. Chitinase activity was determined as a release of soluble Remazol brilliant violet $5 \mathrm{R}$ dye hydrolyzed from insoluble Chitin Azure substrate. The extracted xylem sap contained $19 \mathrm{U}$ of active chitinase per milligram of total protein. In the presence of xylem sap, only minimal germination of the $T$. viride conidia occurred after $24 \mathrm{~h}$ of incubation, whereas preincubation in a $3-\mu \mathrm{M}$ solution of

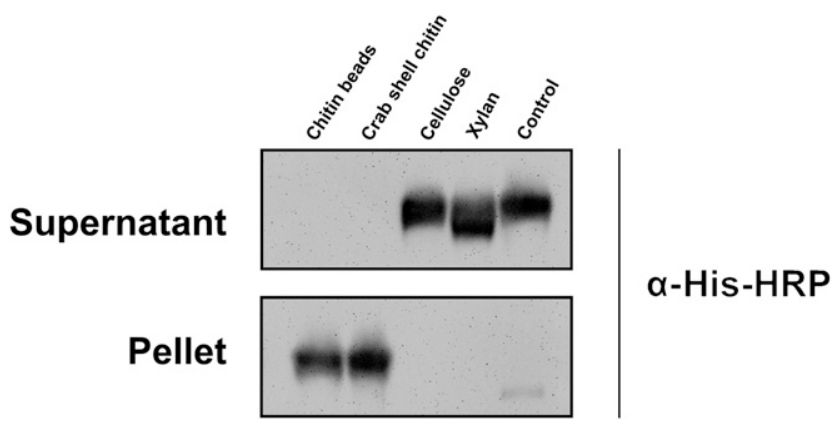

Fig. 3. Carbohydrate sedimentation test confirmed that the recombinant protein VnaChtBP specifically binds to chitin. A recombinant protein (15 $\mu \mathrm{g}$ ) that bound to chitin beads and crab shell chitin was detected in the sediment, and it was present in the supernatant when incubated with cellulose or xylan or without the addition of carbohydrates (control). Western blot analysis was performed with primary antibody His-probe (H-3) (SCBT) $(1: 1,000)$ and secondary chicken antimouse immunoglobulin GHRP (SCBT) (1:5,000). Protein bands were detected using Super Signal West Pico (Thermo-Fisher Scientific) ECL substrate in a GelDoc-It2 Imager (UVP) 
recombinant VnaChtBP prior to the addition of xylem sap enabled germination of conidia and hyphal growth. Interestingly, aggregation and compaction of fungal hyphae were detected only in the presence of both xylem sap and VnaChtBP, while normal mycelial growth without hyphal aggregation was observed in the solution of VnaChtBP (Fig. 5). We assume that VnaChtBP, by binding and probably surrounding chitin fibers in the fungal cell wall, masks chitin and protects it from degradation by xylem sap chitinases.

\section{VnaChtBP suppresses chitin-triggered plant immunity in hop.}

Several fungal chitin-binding effectors prevent chitinmediated PTI trigger (Mentlak et al. 2012; Sánchez-Vallet et al. 2013; Takahara et al. 2016). To test whether VnaChtBP interferes with plant immune responses by sequestering chitin oligomers in the apoplast, the ROS released from the hop suspension cells in response to hexa- $\mathrm{N}$-acetyl chitohexaose $\left[(\mathrm{GlcNAc})_{6}\right]$, in the presence or absence of VnaChtBP, were measured using a chemiluminescent assay. Treatment of hop suspension cells with $1 \mu \mathrm{M}(\mathrm{GlcNAc})_{6}$ resulted in a strong
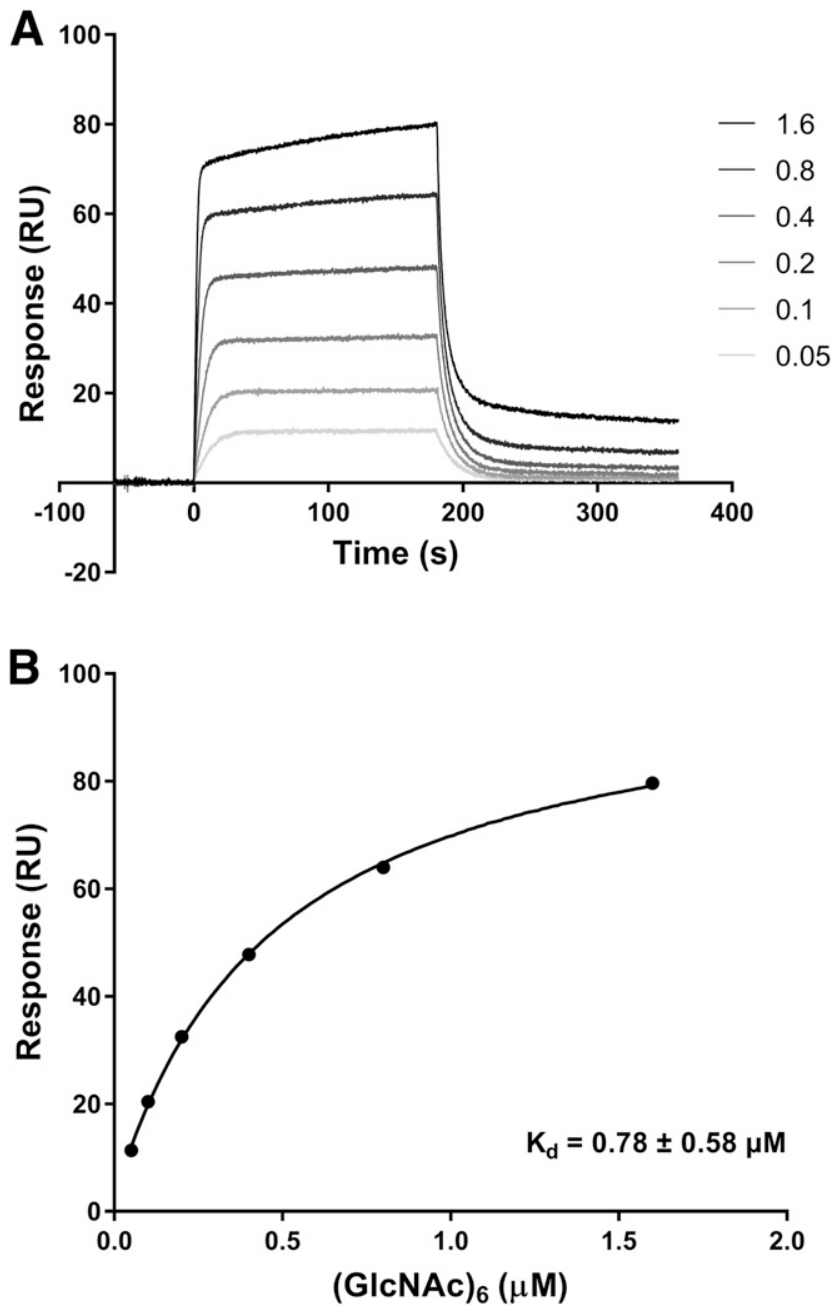

Fig. 4. Surface plasmon resonance analysis of chitin hexamer binding to VnaChtBP. A, Different concentrations $(0.05,0.1,0.2,0.4,0.8,1.6,3.2$, and $6.4 \mu \mathrm{M})$ of hexa-N-acetyl chitohexaose were tested for the binding. B, The binding curve was generated by fitting steady state response levels at the end of the association phase versus the concentration of the injected chitin hexamer. The affinity constant was obtained by fitting the data to the steady-state affinity model. For reproducibility of binding, three independent titration experiments were performed. $\mathrm{RU}=$ response unit. production of ROS, whereas this response was completely abolished in the presence of $5 \mu \mathrm{M}$ VnaChtBP (Fig. 6).

It appears that, similar to LysM effectors, CBM18-containing effector VnaChtBP can suppress chitin-triggered generation of ROS and perturb plant immune responses.

\section{VnaChtBP forms dimers and has two potential binding sites for interaction with chitin.}

Because many chitin-binding proteins have been reported to form dimers (Cao et al. 2014; Liu et al. 2012; Sánchez-Vallet et al. 2013), a yeast-two-hybrid assay was carried out using VnaChtBP as both bait and prey to study the ability to dimerize. Dimer formation of VnaChtBP was detected on a minimal medium using histidine as a reporter (Fig. 7A). Consistent with a weak interaction, only limited growth was observed on triple dropout reporter medium (synthetic complete medium without leucine, tryptophan, and uracil) and the 5-bromo-4-chloro-3indolyl- $\beta$-D-galactoside $(\mathrm{X}$-gal) reporter was not activated. FarUV circular dichroism (CD) spectra of VnaChtBP in the presence and absence of chitin hexamer were obtained to show that binding of chitin to VnaChtBP induces additional secondary structure formation (Fig. 7B). Based on the shape of the spectrum, the secondary structure is predominantly $\alpha$ helical.

To understand the chitin-binding mechanism of CBM18 effectors better, homology modeling of the VnaChtBP threedimensional (3D) structure was performed. The SWISSMODEL server produced three models based on different templates (Table 2). Model02 provided the best fit for four of six CBM18 modules and was used as the basis of the characterization. Molecular docking of the chitin hexamer into the VnaChtBP model (Fig. 7C) shows that each protein monomer contributes to the formation of two binding sites accessible to the ligand. In binding site I (BSI), chitin hexamer is accommodated in a shallow groove formed by four hevein domains of polypeptide chain $A$ and two hevein domains of chain $B$, while binding site II (BSII) comprises four hevein domains of chain B and two domains of chain A. According to the analysis of the presented complex with YASARA, the binding of chitin hexamer in BSI is strengthened by 11 (4 accepted and 7 donated) hydrogen bonds and 8 hydrophobic interactions, which contribute to the total binding energy of $6.891 \mathrm{kcal} / \mathrm{mol}$ (AutoDock Vina) and an estimated docking score of $8.88 \mu \mathrm{M}$. A similar preference for binding of chitin hexamer in the BSII was observed, with an estimated docking score of $2.01 \mu \mathrm{M}$ and a total binding energy of $7.772 \mathrm{kcal} / \mathrm{mol}$, supported by 8 ( 3 accepted and 5 donated) hydrogen bonds and 12 hydrophobic interactions between the ligand and receptor.

VnaChtBP deletion has no significant effect on the growth and pathogenicity of $V$. nonalfalfae.

Because VnaChtBP is specifically expressed during colonization of hop, its contribution to fungal virulence was tested in the susceptible hop variety Celeia. $V$. nonalfalfae knockout mutants of VnaChtBP were generated by targeted gene disruption via Agrobacterium tumefaciens-mediated transformation. Prior to plant inoculation, growth of fungal colonies and sporulation of knockout mutants were assessed in vitro and compared with the wild type (Supplementary Fig. S4). In the selected knockout mutants, mycelial growth and fungal morphology did not differ significantly from the wild type. Reduced sporulation was observed for both mutants compared with the wild type but this did not affect disease frequency. After inoculation of the hop plants, disease symptoms were independently assessed five times using a disease severity index (DSI) with a 0-to-5 scale (Radišek et al. 2003). After the final symptom assessment, the presence of fungus in all inoculated plants was confirmed through reisolation tests. In addition, no 
differences in the relative amount of fungal DNA between the wild type and VnaChtBP mutant strains were observed on the basis of fungal biomass quantification in infected hop at $21 \mathrm{dpi}$.

Disease symptoms were monitored in susceptible hop following infection with the wild-type $V$. nonalfalfae and knockout mutants of VnaChtBP (Fig. 8A). Both VnaChtBP mutants displayed Verticillium wilting symptoms (chlorosis and necrosis of the leaves) in susceptible hop similar to the wild-type fungus, with no significant differences among them according to the DSI assessment (Fig. 8B). Independent pathogenicity assays with additional VnaChtBP deletion mutants yielded the same results (data not shown). This suggests that the VnaChtBP function is redundant for $V$. nonalfalfae infection.

\section{DISCUSSION}

V. nonalfalfae, a soilborne fungal pathogen, causes serious economic damage in European hop-growing regions. Significant efforts have been invested in studying the molecular mechanisms of Verticillium wilt in hop and fungus pathogenicity (Cregeen et al. 2015; Flajšman et al. 2016; Jakše et al. 2013, 2018; Mandelc and Javornik 2015; Marton et al. 2018; Radišek et al. 2006).

In planta expressed fungal proteins are potential effector candidates that might be implicated in pathogen virulence. The effector candidate $V$. nonalfalfae VnaChtBP studied here encodes for a CBM18 domain containing chitin-binding protein and is highly expressed in hop plants. Using an established bioinformatic pipeline (Marton et al. 2018), we identified 11 genes in the $V$. nonalfalfae genome that contain CBM18 domains. Of these genes, two harbored a single CBM18 domain and five, including $V n a C h t B P$, contain a predicted $\mathrm{N}$-terminal signal peptide. Although CBMs play a key role in the recognition of carbohydrates and are known to promote efficient substrate hydrolysis as a part of carbohydrate-active enzymes (e.g., CBM18 motifs found in chitinases), they have also been found to be present in toxins, virulence factors and pathogenesis-associated proteins (Guillén et al. 2010). Proteins containing CBM18 motifs are common in fungi, particularly in plant and animal pathogens. Indeed, they are almost three times more common in the proteomes of pathogens than in those of nonpathogenic fungi across the phylum Ascomycota (Soanes et al. 2008). Intriguingly, in Verticillium spp., CBM18 containing genes are more frequently observed in mildly pathogenic $V$. tricorpus $(n=13)$ (Seidl et al. 2015) than in highly pathogenic $V$. dahliae and $V$. alfalfae $(n=9)$. The expansion of CBM18 domains in ChtBPs may be linked to the evolution of pathogenicity and has, for example, been reported in the fungal pathogen Batrachochytrium dendrobatidis, which has caused a worldwide decline of amphibian populations (Abramyan and Stajich 2012). In total, 18 genes with between 1 and 11 CBM18 domains have been identified in $B$. dendrobatidis, including some classified as lectin-like proteins. Biochemical characterization of three such lectin-like proteins revealed that two have a signal peptide and colocalize with the chitinous cell wall in Saccharomyces cerevisiae. Furthermore, one of these proteins has been shown to bind chitin and thereby protect $T$. reesei from exogenous chitinase, suggesting a role of lectin-like proteins in fungal defense (Liu and Stajich 2015). Similarly, in the rice blast fungus M. oryzae, 15

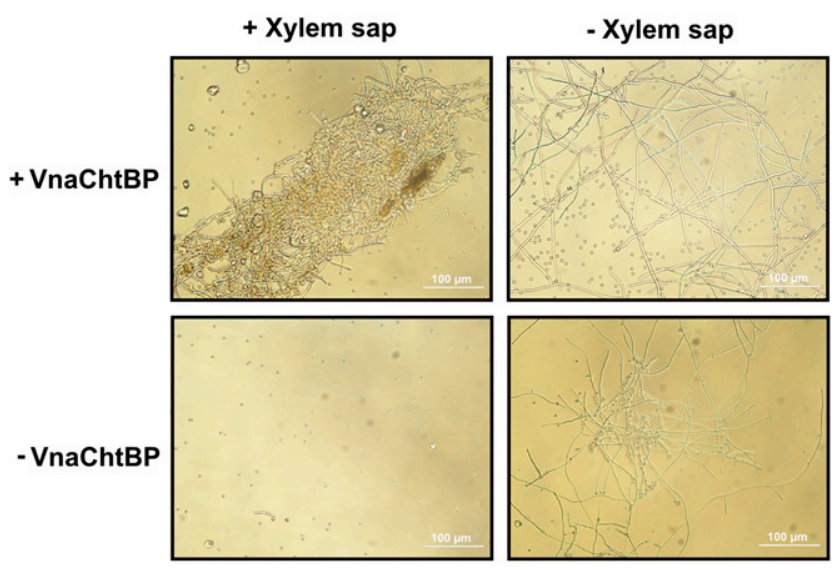

Fig. 5. VnaChtBP protects fungus against degradation by plant chitinases. Micrographs of Trichoderma viride germinating spores, preincubated at room temperature for $2 \mathrm{~h}$ with $3 \mu \mathrm{M}$ VnaChtBP followed by the addition of xylem sap (chitinase at $19 \mathrm{U} / \mathrm{mg}$ of total protein) from Verticillium nonalfalfae-infected hop, were taken $24 \mathrm{~h}$ after treatment. The recombinant protein VnaChtBP caused aggregation and compaction of $T$. viride hyphae and protected the fungus from degradation by xylem sap chitinases. The chitinase activity of xylem sap was measured as a release of dye from Chitin Azure and one chitinase unit was defined as the amount of enzyme that caused a 0.01 increase in absorbance at $575 \mathrm{~nm}$, measured at $\mathrm{pH} 5.0$ and $25^{\circ} \mathrm{C}$.

Table 1. Comparison of chitin oligomer binding affinities of various fungal effectors and plant defense proteins, obtained using isothermal titration calorimetry (ITC) or surface plasmon resonance (SPR) ${ }^{\mathrm{a}}$

\begin{tabular}{|c|c|c|c|c|c|c|}
\hline Organism & Protein & $\mathbf{C A Z y}^{\mathbf{b}}$ & Ligand $^{c}$ & $\mathbf{K}_{\mathbf{d}}(\boldsymbol{\mu} \mathbf{M})^{\mathbf{d}}$ & Method & Reference \\
\hline \multicolumn{7}{|l|}{ Fungus } \\
\hline Cladosporium fulvum & Ecp6 & CBM50 & $(\mathrm{GlcNAc})_{6}$ & $2.8 \times 10^{-4}, 1.7^{\mathrm{e}}$ & ITC & Sánchez-Vallet et al. 2013 \\
\hline Colletotrichum higginsianum & ChELP1 & CBM50 & $(\mathrm{GlcNAc})_{8}-\mathrm{Bio}$ & $2.6 \times 10^{-5}$ & SPR & Takahara et al. 2016 \\
\hline C. higginsianum & ChELP2 & CBM50 & $(\mathrm{GlcNAc})_{8}$-Bio & $2.5 \times 10^{-4}$ & SPR & Takahara et al. 2016 \\
\hline Cladosporium fulvum & Ecp6 & CBM50 & $(\mathrm{GlcNAc})_{8}$ & $1.3 \times 10^{-3}$ & SPR & Mentlak et al. 2012 \\
\hline Magnaporthe oryzae & Slp1 & CBM50 & $(\mathrm{GlcNAc})_{8}$ & $2.4 \times 10^{-3}$ & SPR & Mentlak et al. 2012 \\
\hline Verticillium nonalfalfae & VnaChtBP & CBM18 & $(\mathrm{GlcNAc})_{6}$ & $0.78 \pm 0.58$ & SPR & This study \\
\hline C. fulvum & Avr4 & CBM14 & $(\mathrm{GlcNAc})_{6}$ & $6.3 \pm 0.23$ & ITC & van den Burg et al. 2004 \\
\hline C. fulvum & Ecp6 & CBM50 & $(\mathrm{GlcNAc})_{4,5,6,8}$ & 11.5 to 3.7 & ITC & de Jonge et al. 2010 \\
\hline \multicolumn{7}{|l|}{ Plant } \\
\hline Arabidopsis thaliana & AtLYK5 & CBM50 & $(\mathrm{GlcNAc})_{8}$ & 1.72 & ITC & Cao et al. 2014 \\
\hline Hevea brasiliensis & Hevein & CBM18 & $(\mathrm{GlcNAc})_{5}$ & 2.1 & ITC & Asensio et al. 2000 \\
\hline A. thaliana & AtCERK1 & CBM50 & $(\mathrm{GlcNAc})_{8}$ & 455 & ITC & Cao et al. 2014 \\
\hline A. thaliana & AtCERK1 & CBM50 & $(\mathrm{GlcNAc})_{8}$ & 448 & ITC & Liu et al. 2012 \\
\hline
\end{tabular}

a Proteins are organized according to binding affinity.

b $\mathrm{CBM}=$ carbohydrate-binding module.

c GlcNAc $=\mathrm{N}$-acetylglucosamin and $\mathrm{Bio}=$ biotinylated

${ }^{\mathrm{d}} \mathrm{K}_{\mathrm{d}}=$ affinity constant.

e Ecp6 displays biphasic binding of chitin hexamer in pM range to lysin motif (LysM)1 to LysM3 groove and in $\mu \mathrm{M}$ range to LysM2 domain. 
genes with one to four CBM18 domains were found, although gene-targeted disruption and tolerance to chitinase treatment did not support the implication of the tested genes in fungal pathogenicity (Mochizuki et al. 2011).

VnaChtBP consists of six tandemly repeated CBM18 motifs, contains a signal peptide, and is predicted to reside in the apoplast, which is consistent with the role of chitin binding in the extracellular space. Homology search of proteins that contain CBM18 motifs in other Verticillium spp. revealed that this type of protein is common in pathogenic Verticillium spp. but it seems not to be ubiquitous. For example, in the recently sequenced genomes of five $V$. dahliae strains isolated from strawberry, three strains harbored ChtBPs with 5, 6, and 10 CBM18 motifs, while none were detected in the two other strains.

Monitoring the in planta expression of VnaChtBP showed that it is highly expressed at the later stages of infection in a susceptible hop cultivar, and continues to be expressed even at 30 dpi, when plants exhibit severe wilting symptoms (Cregeen et al. 2015; Marton et al. 2018). In contrast, in a resistant cultivar, the VnaChtBP gene is slightly induced after infection and then completely downregulated. The expression pattern of the $V n a C h t B P$ gene coincides with $V$. nonalfalfae colonization of hop, whereby the fungus spread is unimpeded in susceptible plants, while colonization is arrested approximately 12 to 20 dpi in resistant hop plants, presumably due to strong plant resistance responses (Cregeen et al. 2015). The immune reaction in the incompatible interaction is unlikely to impose selection pressure on the VnaChtBP gene because no allelic polymorphisms were detected among the analyzed $V$. nonalfalfae isolates. Similarly, no allelic variation was found in the closest $(97 \%$ identity) homolog to the VnaChtBP gene from isolates of $V$. alfalfae, suggesting highly conserved genes. Allelic variation is commonly detected in fungal proteins that function as avirulence (Avr) determinants on perception by the host defense but not necessarily in virulence factors of the pathogen (Stergiopoulos et al. 2007). Taken together, we speculate that the absence of allelic variation and the high gene expression observed in planta

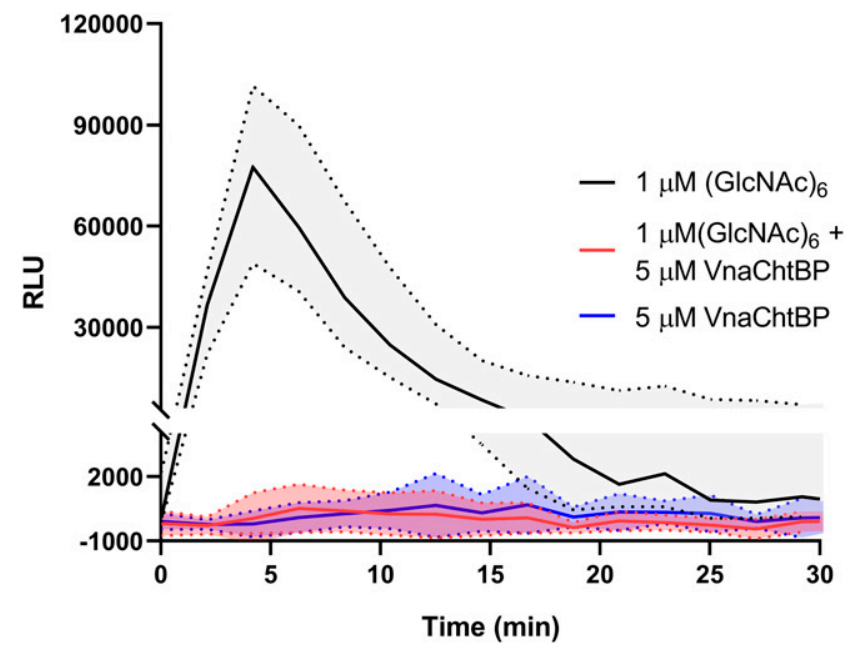

Fig. 6. VnaChtBP prevents chitin-induced activation of plant immune receptors. Reactive oxygen species (ROS) released from hop suspension cells in response to chitin hexamer hexa-N-acetyl chitohexaose [(GlcNAc $\left.)_{6}\right]$ were measured using a chemiluminescent assay with $100 \mu \mathrm{M}$ luminolbased substrate L-012 and horseradish peroxidase at $40 \mu \mathrm{g} / \mathrm{ml}$. Generation of ROS was elicited with $1 \mu \mathrm{M}$ (GlcNAc) ${ }_{6}$ in the absence and presence of $5 \mu \mathrm{M}$ VnaChtBP or with $5 \mu \mathrm{M}$ VnaChtBP for control. Data were background corrected and presented as a median with $95 \%$ confidence interval of five measurements. The area under the curve of the chitin-treated group, VnaChtBP-treated group, and the chitin plus VnaChtBP group were compared using a nonparametric Kruskal-Wallis test with Holm's post hoc analysis $\left(P\right.$ value $\left.<2 \cdot 2 \mathrm{e}^{-16}\right)$. RLU $=$ relative luminiscence units. suggest a role for $\mathrm{VnaChtBP}$ in the virulence of $V$. nonalfalfae. However, in a pathogenicity assay, VnaChtBP-targeted deletion mutants were not significantly impaired in their hops infectivity compared with wild-type fungus, which is in line with functional redundancy. Unchanged virulence of deletion mutants, presumably due to functional redundancy, has been reported for two other tested CBM18-containing ChtBPs in M. oryzae (Mochizuki et al. 2011) and also for LysM fungal effector Mg1LysM of Mycosphaerella graminicola (Marshall et al. 2011). Indeed, seven putative chitin-binding LysM effectors have been found in the $V$. nonalfalfae genome, which may have a role in protection of the fungal cell wall chitin or may interfere with chitin-triggered plant immunity. Orthologs of Cladosporium fulvum Avr4 with the CBM14 chitin-binding motif were not identified in the $V$. nonalfalfae genome (Jakše et al. 2018) or in the predicted proteomes of other Verticillium spp. (Seidl et al. 2015).
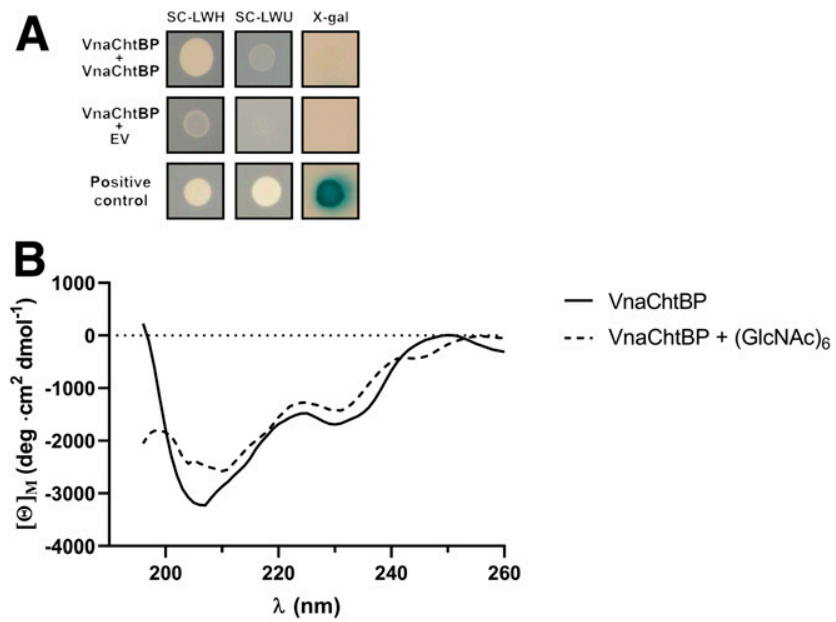

C

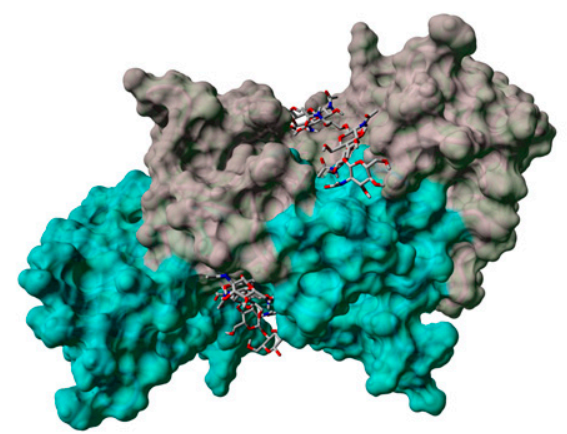

Fig. 7. Confirmation of VnaChtBP dimerization, circular dichroism (CD) spectra of VnaChtBP in the absence and presence of chitin hexamer, and a schematic representation of the VnaChtBP homology model in complex with chitin hexamer. A, Effector gene VnaChtBP was cloned into the vectors pDEST22 and pDEST32 to serve as both bait and prey and yeasttwo-hybrid assay was performed. Weak dimerization of the effector was confirmed on a triple dropout reporter synthetic complete medium without leucine, tryptophan, and histidine (SC-LWH) and no self-activation of the pDEST22 construct with empty pDEST32 vector was detected on the 5bromo-4-chloro-3-indolyl- $\beta$-D-galactoside (X-gal) reporter. SC-LWU = synthetic complete medium without leucine, tryptophan, and uracil and $\mathrm{EV}=$ empty vector. $\mathbf{B}, \mathrm{CD}$ spectra of $2.5 \mu \mathrm{M}$ VnaChtBP in the absence and presence of $25 \mu \mathrm{M}$ chitin hexamer [hexa-N-acetyl chitohexaose (GlcNAc) 6 ] were recorded on a Jasco $\mathrm{J}-1500 \mathrm{CD}$ spectrometer at $25^{\circ} \mathrm{C}$ and $\mathrm{pH}$ 8.0. Binding of chitin hexamer to VnaChtBP induced additional secondary structure formation. C, The three-dimensional model of VnaChtBP obtained by Swiss-Model (Arnold et al. 2006; Waterhouse et al. 2018) was refined by YASARA Structure (Krieger and Vriend 2014, 2015) and used in YASARA's AutoDock Vina module (Trott and Olson 2010) for molecular docking of chitin hexamer, built in the SWEET PROGRAM (Bohne et al. 1998, 1999). VnaChtBP is in dimeric form and the chitin-binding domains of chain A are in cyan and chain B in gray. The chitin hexamer is shown in stick representation. 
Consistent with previously characterized CBM18-containing proteins from Magnaporthe oryzae (Mochizuki et al. 2011) and B. dendrobatidis (Liu and Stajich 2015), recombinant VnaChtBP binds specifically to chitin beads and crab shell chitin but not to plant cell wall cellulose or xylan. In addition to chitin polymer, recombinant VnaChtBP also bound chitin hexamer in an SPR experiment, with binding affinity in the submicromolar range. Compared with plant chitin receptors, recombinant VnaChtBP together with LysM effectors Ecp6 from C. fulvum, Slp1 from M. oryzae (Mentlak et al. 2012), and ChELP1 and ChELP2 from Colletotrichum higginsianum (Takahara et al. 2016) exhibit three to five orders of magnitude higher affinity to chitin oligomers. Thus, it is not surprising that these fungal effectors are able to outcompete plant chitin receptors such as Arabidopsis thaliana AtLYK5 (Cao et al. 2014) and AtCERK1 (Liu et al. 2012).

Based on nuclear magnetic resonance studies and solved crystal structures of plant LysM chitin receptors, several mechanisms for binding of chitin have been proposed, from a simple "continuous groove" model for AtCERK1 (Liu et al. 2012) to the OsCEBiP "sandwich" (Hayafune et al. 2014) and "sliding mode" model (Liu et al. 2016). However, these models have been unable to explain the observed elicitor activities of chitin oligomers. Building on these models and using a range of chitosan polymers and oligomers bound to Atcerkl mutants resulted in an improved "slipped sandwich" model that fits all experimental results (Gubaeva et al. 2018). A recent structural study of fungal LysM effector Ecp6 from Cladosporium fulvum revealed a novel chitinbinding mechanism that explained how LysM effectors can outcompete plant host receptors for chitin binding (SánchezVallet et al. 2013). Ecp6 consists of three tightly packed LysM domains, with a typical $\beta \alpha \alpha \beta$ fold. Intrachain dimerization of chitin-binding regions of LysM1 and LysM3 leads to the formation of a deeply buried chitin-binding groove with an ultrahigh (pM) affinity. The remaining LysM2 domain also binds chitin, albeit with low micromolar affinity, and interferes with chitin-triggered immunity, possibly by preventing chitin immune receptor dimerization and not by chitin fragment sequestering, as in the case of LysM1 to LysM3.

To date, to the best of our knowledge, the molecular mechanism of chitin binding of CBM18 fungal effectors remains elusive. However, the 3D homology model of VnaChtBP provides a tangible model for the molecular docking of the chitin hexamer. Although only four of six CBM18 domains could be reliably modeled, the analysis revealed that VnaChtBP dimerizes. Importantly, this prediction was independently validated through a yeast-two-hybrid experiment. The VnaChtBP complex has two putative chitin-binding sites, which form a shallow binding cleft by cooperation of the two polypeptide chains and have a similar preference to chitin. As in CBM18 lectin-like plant defense proteins (Jiménez-Barbero et al. 2006), typically represented by a small antifungal protein hevein from the rubber tree (Hevea brasiliensis), a network of hydrogen bonds and several hydrophobic interactions occur between VnaChtBP residues and $\mathrm{N}$-acetyl moieties of the chitin oligomer. These are thought to stabilize the interaction and contribute to submicromolar chitin-binding affinity, as determined by $\mathrm{CD}$ and SPR experiments, respectively. Similarly, the recently solved crystal structure of fungal effector CfAvr4, a CBM14 lectin, in complex with chitin hexamer (Hurlburt et al. 2018), revealed that two effector molecules form a sandwich structure, which encloses two parallel stacked chitin hexamer molecules, shifted by one sugar ring, in an extended chitin-binding site. In this complex, the interaction is mediated through aromatic residues and numerous hydrogen bonds, with both side chains and main chains. Interestingly, no intermolecular proteinprotein interactions have been observed across the dimer, suggesting ligand-induced effector dimerization.

Fungal plant pathogens have evolved several strategies to escape the surveillance of chitin-related immune systems (Sánchez-Vallet et al. 2015). The various mechanisms used include conversion of chitin to chitosan by chitin deacetylases and inclusion of $\alpha-1,3$-glucan in the cell walls, as well as secretion of diverse effectors that can shield the fungal hyphae from hydrolysis by plant chitinases, directly inhibiting their activity, acting as scavengers of chitin fragments, or preventing chitin-induced plant immunity. Suppression of chitin-triggered
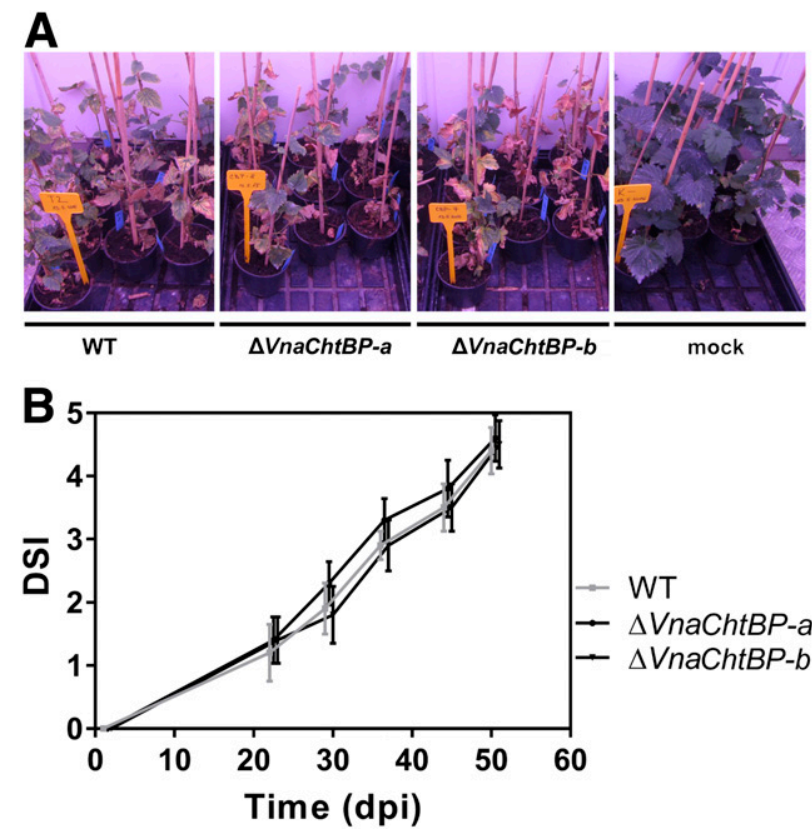

Fig. 8. A, Symptom development and disease severity index (DSI) assessment in susceptible hop following infection with the wild type (WT) Verticillium nonalfalfae and two knockout mutants of VnaChtBP. Plants of susceptible hop Celeia were inoculated by root dipping in a $5 \times 10^{6}$ con$\mathrm{idia} / \mathrm{ml}$ suspension and Verticillium wilting symptoms were assessed five times postinoculation. A, Both VnaChtBP deletion mutants displayed Verticillium wilting symptoms (chlorosis and necrosis of the leaves) in susceptible hop similar to the WT fungus. Pictures were taken 35 days postinoculation (dpi). B, According to the DSI assessment with a 0-to-5 scale (Radišek et al. 2003), there were no significant differences between the WT V. nonalfalfae and knockout mutants of VnaChtBP. Means with standard error were calculated for 10 plants/treatment.

Table 2. Results of homology modeling of the VnaChtBP using the SWISS-MODEL server

\begin{tabular}{|c|c|c|c|c|c|c|c|}
\hline Model & Template & Description & Seq ID $(\%)^{a}$ & Oligo-states & GMQE $^{\mathbf{b}}$ & QMEAN $^{c}$ & Coverage \\
\hline Model01 & 2uwg.1.A & Wheat germ lectin & 43.98 & Homo-dimer & 0.31 & -4.61 & 98 to 318 \\
\hline Model02 & 2wgc.1.A & Agglutin isolectin 1 & 40.96 & Homo-dimer & 0.32 & -3.22 & 39 to 254 \\
\hline Model03 & 1ulk.1.A & Lectin-C & 49.15 & Homo-dimer & 0.20 & -0.65 & 212 to 378 \\
\hline
\end{tabular}

\footnotetext{
a Sequence identity.

${ }^{\mathrm{b}}$ GMQE = global model quality estimation.

${ }^{c}$ QMEAN = qualitative model energy analysis, a composite scoring function describing the major geometrical aspects of protein structures.
} 
immunity has been demonstrated for some LysM effectors with subnanomolar affinity for chitin oligomers (Kombrink et al. 2017; Mentlak et al. 2012; Sánchez-Vallet et al. 2013; Takahara et al. 2016). Here, we find that VnaChtBP binds to chitin oligomers with submicromolar affinity, preventing free chitin oligomers from binding to plant immune receptors and, thus, suppressing ROS-related defense responses in hop. A protective role against host chitinases has been shown for secreted effector Avr4 from C. fulvum, which binds to fungal cell wall chitin to reduce its accessibility to host chitinases (van den Burg et al. 2006). Similar to CfAvr4, wheat pathogen M. graminicola secreted effectors Mg1LysM and Mg3LysM and $V$. dahliae effector Vd2LysM protect fungal hyphae from hydrolysis by plant chitinases (Kombrink et al. 2017; Marshall et al. 2011). We provide evidence that, in addition to Avr4 (CBM14) and LysM (CBM50) effectors, structurally unrelated CBM18 lectinlike proteins that are found in fungal pathogens of plants (this study) and amphibian pathogens (Liu and Stajich 2015) have evolved a chitin shielding ability against plant chitinases.

\section{MATERIALS AND METHODS}

\section{Cultivation of microorganisms.}

E. coli MAX Efficiency DH5 $\alpha$ or MAX Efficiency DH10B (both from Invitrogen, Thermo-Fisher Scientific) was used for plasmid propagation and were grown at $37^{\circ} \mathrm{C}$ on Luria-Bertani agar plates or liquid medium supplemented with appropriate antibiotics (carbenicillin at $100 \mathrm{mg} / \mathrm{liter}$, kanamycin at $50 \mathrm{mg} / \mathrm{liter}$, or gentamicin at $25 \mathrm{mg} / \mathrm{liter}$ ). E. coli Shuffle T7 (New England Biolabs [NEB]) was propagated at $30^{\circ} \mathrm{C}$ and protein expression was performed at $16^{\circ} \mathrm{C}$. T. viride was obtained from The Microbial Culture Collection Ex (IC Mycosmo [MRIC UL]) and all Verticillium strains were from the Slovenian Institute of Hop Research and Brewing fungal collection. Fungi were grown at $24^{\circ} \mathrm{C}$ in the dark on $1 / 2$ Czapek-Dox agar plates or liquid medium. Knockout mutants were retrieved from selection medium supplemented with timentin at $150 \mathrm{mg} / \mathrm{liter}$ and hygromycin at $75 \mathrm{mg} / \mathrm{liter}$.

\section{RNA sequencing.}

RNA-Seq library preparation from $V$. nonalfalfae-infected hop at $6,12,18$, and $30 \mathrm{dpi}$ and data processing have been previously described (Progar et al. 2017). Fungal transcripts were filtered out and their gene expression profiles were generated using the hierarchical clustering with Euclidean distance method in $\mathrm{R}$ language ( $\mathrm{R}$ Core Team 2016). Data were presented as a matrix of $\log _{2}$ counts per million (number of reads mapped to a gene model per million reads mapped to the library) expression values.

\section{VnaChtBP gene expression profiling with RT-qPCR.}

The expression of $V n a C h t B P$ was quantified by RT-qPCR in hop infected with $V$. nonalfalfae isolate T2. Total RNA was extracted at 6, 12, and 18 dpi using a Spectrum Plant total RNA kit (Sigma-Aldrich) and $1 \mu \mathrm{g}$ was reverse transcribed to cDNA using a High-Capacity cDNA reverse transcription kit (Applied Biosystems). The qPCR was run in five biological and two technical replicates on an ABI PRISM 7500 (Applied Biosystems), under the following conditions: denaturation at $95^{\circ} \mathrm{C}$ for $10 \mathrm{~min}$ followed by 40 cycles at $95^{\circ} \mathrm{C}$ for $10 \mathrm{~s}, 60^{\circ} \mathrm{C}$ for $30 \mathrm{~s}$, and consisted of: $50 \mathrm{ng}$ of cDNA; $300 \mathrm{nM}$ forward and reverse primer; and $5 \mu \mathrm{l}$ of Fast SYBR Green master mix (Roche). The results were analyzed using the $\Delta \Delta \mathrm{C}_{\mathrm{t}}$ method (Schmittgen and Livak 2008). Transcription levels of $V n a C h t B P$ were quantified relative to its expression in liquid Czapek-Dox medium and normalized to fungal biomass in hop using topoisomerase and splicing factor as reference genes (Marton et al. 2018). One-way analysis of variance (ANOVA) with Tukey's post hoc test was performed to test for differences between the group means. Primers used are listed in Supplementary Table S3.

\section{Genetic analysis.}

Genomic DNA was extracted from 7- to 10-day-old potato dextrose agar-cultured Verticillium isolates by the cetyltrimethylammonium bromide (CTAB) extraction method (Möller et al. 1992). PCRs were performed in $50 \mu \mathrm{l}$ using Q5 High-Fidelity DNA Polymerase (NEB), $500 \mathrm{nM}$ gene-specific primers, and $100 \mathrm{ng}$ of DNA under the following conditions: denaturation at $95^{\circ} \mathrm{C}$ for $10 \mathrm{~min}$; followed by 40 cycles at $95^{\circ} \mathrm{C}$ for $10 \mathrm{~s}, 58^{\circ} \mathrm{C}$ for $30 \mathrm{~s}$, and $72^{\circ} \mathrm{C}$ for $90 \mathrm{~s}$; and a final elongation step at $72^{\circ} \mathrm{C}$ for $90 \mathrm{~s}$. PCR products were purified from agarose gel (Silica Bead DNA Gel Extraction Kit; Fermentas), cloned into pGEM-T Easy vector (Promega Corp.), and sequenced using Sanger technology with gene-specific and plasmidspecific primers. Sequences were analyzed using CodonCode Aligner V7.1.2 (CodonCode Co.) and deposited at the NCBI.

\section{Bioinformatic analysis.}

A putative localization of VnaChtBP to the apoplast was predicted with ApoplastP 1.0 (Sperschneider et al. 2018). To classify V. nonalfalfae CBM18-containing proteins functionally, sequence-based searches were carried out using the FunFHMMer web server at the CATH-Gene3D database (Dawson et al. 2017). To obtain VnaChtBP homologs, the amino acid sequence of VnaChtBP was used as a query for NCBI BLAST+ against UniProt Knowledgebase at Interpro (Li et al. 2015).

\section{Yeast two-hybrid assay (Y2H).}

Dimerization of VnaChtBP was examined with a yeast-twohybrid experiment using the ProQuest $\mathrm{Y} 2 \mathrm{H}$ system (Invitrogen). To generate bait and prey vectors, the VnaChtBP gene was cloned into pDEST22 and pDEST32, respectively, and cotransformed in yeast. The interactors were confirmed by plating the yeast cotransformants on triple-dropout reporter synthetic complete medium without leucine, tryptophan, and histidine; on triple-dropout reporter synthetic complete medium without leucine, tryptophan, and uracil; and by performing an X-gal assay. The self-activation test of a pDEST22 construct containing the VnaChtBP gene with empty pDEST32 vectors was also performed.

\section{D modeling and molecular docking.}

The SWISS-MODEL (Arnold et al. 2006; Waterhouse et al. 2018) server produced three models based on different templates, and Model02 was selected for further modeling. The output protein structure was additionally minimized in explicit water using an AMBER14 force field (Duan et al. 2003) and em_runclean.mcr script within YASARA Structure (Krieger and Vriend 2014, 2015). A 3D structure model of chitin hexamer was built with SWEET PROGRAM v.2 (Bohne et al. 1998, 1999), saved as a PDB file, and used as a ligand in subsequent molecular docking experiments with AutoDock Vina (Trott and Olson 2010), which is incorporated into YASARA Structure. To ensure the integrity of docking results, 200 independent dockings of the ligand to the receptor were performed. The pose with the best docking score was selected for further refinement using md_refine.mcr script provided by YASARA Structure. The final model of the hexameric chitin bound to the VnaChtBP dimer was then used for the analysis.

\section{Recombinant protein production.}

VnaChtBP DNA without the predicted signal peptide (SignalP 4.1) was cloned into a pET32a expression vector using a Gibson Assembly Cloning Kit (NEB). The protein expression 
in E. coli SHuffle T7 cells (NEB) was induced at an optical density at $600 \mathrm{~nm}=0.6$ with $1 \mathrm{mM}$ isopropyl- $\beta$-D-thiogalactoside and incubated overnight at $16^{\circ} \mathrm{C}$. The recombinant protein was solubilized from inclusion bodies using a mild solubilization method (Qi et al. 2015). Briefly, pelleted cells were resuspended in cold phosphate-buffered saline (PBS) buffer and disrupted by sonication. After centrifugation, the pellet was washed with PBS, resuspended in urea, frozen at $-20^{\circ} \mathrm{C}$, and allowed to slowly thaw at room temperature. The recombinant protein was purified using Ni-NTA Spin Columns (Qiagen) according to the manufacturer's protocol, aliquoted, and stored in $20 \mathrm{mM}$ Tris $(\mathrm{pH} 8.0)$ at $-80^{\circ} \mathrm{C}$.

\section{Carbohydrate sedimentation assay and Western blot detection.}

The carbohydrate sedimentation assay was adapted from van den Burg et al. (2006). Briefly, $15 \mu \mathrm{g}$ of recombinant VnaChtBP in $20 \mathrm{mM}$ Tris ( $\mathrm{pH} 8.0$ ) was mixed with $1.5 \mathrm{mg}$ of chitin magnetic beads (NEB), crab shell chitin (SigmaAldrich), cellulose (Sigma-Aldrich), or xylan (Apollo Scientific) and incubated at room temperature for $2 \mathrm{~h}$ on an orbital shaker at $350 \mathrm{rpm}$. The same amount of protein in Tris buffer without added carbohydrates was used as a negative control. After centrifugation $(5 \mathrm{~min}, 13,000 \times g)$, the supernatant was collected and the pellet was washed three times with $800 \mu \mathrm{l}$ of $20 \mathrm{mM}$ Tris ( $\mathrm{pH}$ 8.0) prior to resuspension in $4 \times$ Bolt LDS Sample Buffer with the addition of reducing agent (Invitrogen).

The presence of VnaChtBP in different fractions was determined by Western blot analysis. Samples $(25 \mu \mathrm{l})$ were loaded on a precast Bolt 4 to $12 \%$ Bis-Tris gel (Invitrogen) and SDSPAGE in $1 \times$ morpholinepropanesulfonic acid running buffer was performed using a Mini Gel Tank (Thermo-Fisher Scientific) for $30 \mathrm{~min}$ at $200 \mathrm{~V}$. Proteins were transferred for $1 \mathrm{~h}$ at $30 \mathrm{~V}$ to an Invitrolon polyvinylidene diflouride membrane (Invitrogen) and Ponceau S stained. The membrane was blocked with $5 \%$ bovine serum albumen in $1 \times$ PBS before the addition of the primary antibody His-probe (H-3) (SCBT) (1:1,000). The membrane was incubated overnight at $4^{\circ} \mathrm{C}$, washed with $1 \times \mathrm{PBS}$, and incubated in a solution of secondary chicken antimouse immunoglobulin G-HRP (SCBT) $(1: 5,000)$ for $1 \mathrm{~h}$. Protein bands were detected using Super Signal West Pico (Thermo-Fisher Scientific) ECL substrate in a GelDoc-It2 Imager (UVP).

\section{Surface plasmon resonance.}

The binding of (GlcNAc) 6 (IsoSep) to VnaChtBP was measured using a Biacore T100 analytical system and CM5 sensor chip (Biacore; GE Healthcare). The CM5 sensor chip was activated using an Amine coupling Kit (GE Healthcare) according to the manufacturer's instructions. VnaChtBP was diluted into $10 \mathrm{mM}$ sodium acetate $(\mathrm{pH} 5.1)$ to a final concentration of $0.1 \mathrm{mg} / \mathrm{ml}$ and injected for $5 \mathrm{~min}$ over the second flow cell. The first flow cell was empty and served as a reference cell to control the level of nonspecific binding. The final immobilization level was approximately 10,000 response units. The (GlcNAc) $)_{6}$ stock solution was diluted into a series of concentrations $(0.05,0.1,0.2,0.4,0.8,1.6,3.2$, and $6.4 \mu \mathrm{M})$ with HBS buffer (10 mM $N$-2-hydroxyethylpiperazine- $N$ '-2-ethanesulfonic acid and $140 \mathrm{mM} \mathrm{NaCl}, \mathrm{pH} 7.4$ ) and assayed to detect direct binding to VnaChtBP. Titration was performed in triplicate. In addition to chitin hexamer, $\mathrm{N}$-acetyl glucosamine, glucosamine, glucose, galactose, and mannose were tested at a $500 \mu \mathrm{M}$ concentration in HBS buffer. Biacore T100 Evaluation software was used to assess the results. First, the sensorgrams were reference and blank subtracted; then, a steady-state affinity model was applied to calculate the affinity constant $\left(K_{d}\right)$. The average of three repeated experiments was used for final $\mathrm{K}_{\mathrm{d}}$ determination.

\section{CD spectra.}

Far-UV CD spectra were recorded on a Jasco J-1500 CD spectrometer from 190 to $260 \mathrm{~nm}$ at $25^{\circ} \mathrm{C}$ using a $0.1-\mathrm{cm}$ pathlength quartz cuvette. The VnaChtBP concentration in $20 \mathrm{mM}$ Tris (pH 8.0) was $2.5 \mu \mathrm{M}$ and (GlcNAc) 6 (Santa Cruz Biotechnology) was at $25 \mu \mathrm{M}$ final concentration. Measurements were performed at a 1-nm interval and scanning speed of $5 \mathrm{~nm} / \mathrm{min}$ by using a $1-\mathrm{nm}$ bandwidth. Final spectra were baseline corrected and transformed to mean residue ellipticity using a mean residue weight of VnaChtBP of 99.851 Da.

\section{Xylem sap extraction and chitinase activity assay.}

Xylem sap was extracted from infected hop plants in a pressure chamber at $0.2 \mathrm{MPa}$ for $120 \mathrm{~min}$ (Flajšman et al. 2018). The chitinase activity of xylem sap was determined by mixing $150 \mu \mathrm{l}$ of xylem sap, or $100 \mathrm{mM}$ Na-acetate (pH 5.0) buffer as negative control, with $1.5 \mathrm{mg}$ of Chitin Azure (SigmaAldrich) dissolved in $150 \mu \mathrm{l}$ of $100 \mathrm{mM} \mathrm{Na}$-acetate (pH 5.0). The samples were incubated for $150 \mathrm{~min}$ at $25^{\circ} \mathrm{C}$ on a rotary shaker at $70 \mathrm{rpm}$. An aliquot of $80 \mu \mathrm{l}$ was taken immediately (blank sample) and after $150 \mathrm{~min}$. The reaction was stopped with the addition of $20 \%$ ( $\mathrm{vol} / \mathrm{vol}) \mathrm{HCl}$ and samples were centrifuged for $10 \mathrm{~min}$ at $10,000 \times g$. The chitinase activity of xylem sap in the supernatant was determined by measuring the absorbance of released Remazol Brilliant Blue dye at $575 \mathrm{~nm}$ against $100 \mathrm{mM}$ Na-acetate ( $\mathrm{pH}$ 5.0). One enzyme unit was defined as the amount of chitinase that produced a 0.01 increase in absorbance at $575 \mathrm{~nm}$, measured at $25^{\circ} \mathrm{C}$ and $\mathrm{pH}$ 5.0. The total protein concentration of the xylem sap was measured in a $10 \times$ diluted sample using a Pierce BCA Protein Assay Kit (Thermo-Fisher Scientific) following the standard protocol.

\section{Cell protection assay.}

The cell protection assay was adapted from (Mentlak et al. 2012). T. viride conidia were harvested, diluted to 2,000 conidia/ml in $50 \mu \mathrm{l}$ of $1 / 2$ Czapek-Dox medium, and incubated overnight. After germination of the conidia, $25 \mu \mathrm{l}$ of recombinant VnaChtBP ( $3 \mu \mathrm{M}$ final concentration) or an equal volume of storage buffer (20 mM Tris, $\mathrm{pH}$ 8.0) was added and the conidial suspensions were incubated for $2 \mathrm{~h}$. Fungal cell wall hydrolysis was triggered by the addition of $25 \mu$ of xylem sap as a source of plant chitinases, while $25 \mu \mathrm{l}$ of Na-acetate (100 mM, pH 5.0) was used in the control experiment. After $24 \mathrm{~h}$ of incubation, mycelia formation and fungal growth were examined using a Nikon Eclipse 600 microscope.

\section{ROS production.}

Hop suspension cells were prepared from hop tissue culture (obtained from the Slovenian Institute of Hop Research and Brewing), as described previously (Langezaal and Scheffer 1992). Briefly, the internodal segments were cultured on solid Murashige and Skoog (MS) media supplemented with 2,4dichlorophenoxyacetic acid at $1 \mathrm{mg} / \mathrm{liter}$ and kinetin at 1 $\mathrm{mg} / \mathrm{liter}$ and calluses were subcultured every 2 weeks. For initiation of suspension cell culture, $5 \mathrm{~g}$ of fresh callus were resuspended in $50 \mathrm{ml}$ of liquid MS media, grown in the dark at $140 \mathrm{rpm}$, then maintained by subculturing every 2 weeks.

One-week-old hop suspension cells were harvested by centrifugation and MS medium was replaced by sterile distilled water prior to ROS measurements. For each treatment, a $150-\mu 1$ aliquot of suspension cells was mixed with a $150-\mu 1$ assay solution containing $100 \mu \mathrm{M}$ L-012 substrate (Sigma), horseradish peroxidase (Sigma) at $40 \mu \mathrm{g} / \mathrm{ml}$, and either $1 \mu \mathrm{M}$ chitin [(GlcNAc) $)_{6}$; Santa Cruz Biotechnology], $5 \mu \mathrm{M}$ VnaChtBP, a combination of $1 \mu \mathrm{M}$ chitin [(GlcNAc $\left.)_{6}\right]$ and $5 \mu \mathrm{M}$ VnaChtBP, or sterile distilled water as a negative control. Luminol-based chemiluminescence measurements were recorded for $30 \mathrm{~min}$ at 
a minimal interval (of 2 min $5 \mathrm{~s}$ ) in a Synergy $\mathrm{H} 1$ microplate reader (BioTek Instruments). Data were baseline corrected and presented as a median with $95 \%$ confidence interval of five measurements. R package DescTools (Signorell 2017) was used to calculate the area under the curve. A nonparametric Kruskal-Wallis test with Holm's post hoc analysis was used to test the differences between the chitin-treated group, VnaChtBP-treated group, and the chitin plus VnaChtBP group.

\section{Pathogenicity assay.}

VnaChtBP knockout mutants were generated using the Agrobacterium tumefaciens-mediated transformation protocol described previously (Flajšman et al. 2016). Before the pathogenicity tests were carried out, fungal growth and sporulation were inspected, as described previously (Flajšman et al. 2017). Briefly, sporulation of fungal samples from liquid Czapek-Dox medium was assessed using a Thoma cell-counting chamber under a light microscope. Wild-type strain T2 was attributed grade 5, indicating $100 \%$ sporulation (typically reaching $10^{7}$ spores/ml after 1 week). Sporulation of mutant strains was then compared with that of the wild type on a scale from 0 to 5 , with a $20 \%$ interval.

For the pathogenicity assay, 10 plants of the Verticillium wilt-susceptible hop cultivar Celeia were inoculated by $10-\mathrm{min}$ root dipping in a conidial suspension $\left(5 \times 10^{6}\right.$ conidia/ml $)$ of two arbitrarily selected VnaChtBP knockout mutants. Conidia of the wild-type $V$. nonalfalfae isolate T2 served as a positive control and sterile distilled water was used as a mock control. Repotted plants were grown under controlled conditions in a growth chamber (Flajšman et al. 2017). Verticillium wilting symptoms were assessed five times over 7 weeks postinoculation using a DSI with a 0-to-5 scale (Radišek et al. 2003). After symptom assessment, a fungal reisolation test (Flajšman et al. 2017) was performed to confirm infection of the tested hop plants.

In addition, fungal biomass quantification was carried out in five hop plants infected with either wild-type or VnaChtBP mutant $V$. nonalfalfae strains. Samples were collected at $21 \mathrm{dpi}$ and total genomic DNA was extracted using the CTAB protocol (Möller et al. 1992). Fungal DNA was quantified on the Applied Biosystems 7500 RT-qPCR system (Applied Biosystems) using Fast SYBR Green technology (Thermo-Fisher Scientific) and $V$. nonalfalfae lethal genotype (PG2)-specific primer 5-1gs (Radišek et al. 2004). The relative quantity of $V$. nonalfalfae DNA in infected hop was estimated with the $2^{-\Delta \Delta C t}$ method (Schmittgen and Livak 2008) using the hop reference gene DEAD box RNA helicase 1 for normalization (Štajner et al. 2013). One-way ANOVA with Tukey's multiple comparison test was performed in GraphPad Prism 8.02 (GraphPad Software) to test for differences between the wild-type and mutant group means.

\section{ACKNOWLEDGMENTS}

We thank V. Progar for transcriptome analysis; V. Hodnik for SPR analysis; and M. Armstrong, M. Bahun, U. Kunej, M. Dolinar, J. Jakše, and N. P. Ulrih for technical advice.

\section{AUTHOR-RECOMMENDED INTERNET RESOURCES}

COST Action: https://www.cost-sustain.org

GraphPad Software: https://www.graphpad.com/

\section{LITERATURE CITED}

Abramyan, J., and Stajich, J. E. 2012. Species-specific chitin-binding module 18 expansion in the amphibian pathogen Batrachochytrium dendrobatidis. MBio 3:e00150-12.
Akcapinar, G. B., Kappel, L., Sezerman, O. U., and Seidl-Seiboth, V. 2015. Molecular diversity of LysM carbohydrate-binding motifs in fungi. Curr Genet. 61:103-113.

Andersen, N. H., Cao, B., Rodríguez-Romero, A., and Arreguin, B. 1993. Hevein: NMR assignment and assessment of solution-state folding for the agglutinin-toxin motif. Biochemistry 32:1407-1422.

Arnold, K., Bordoli, L., Kopp, J., and Schwede, T. 2006. The SWISSMODEL workspace: A web-based environment for protein structure homology modelling. Bioinformatics 22:195-201.

Asensio, J. L., Cañada, F. J., Siebert, H.-C., Laynez, J., Poveda, A., Nieto, P. M., Soedjanaamadja, U. M., Gabius, H.-J., and Jiménez-Barbero, J. 2000. Structural basis for chitin recognition by defense proteins: GlcNAc residues are bound in a multivalent fashion by extended binding sites in hevein domains. Chem. Biol. 7:529-543.

Böhm, H., Albert, I., Fan, L., Reinhard, A., and Nürnberger, T. 2014. Immune receptor complexes at the plant cell surface. Curr. Opin. Plant Biol. 20:47-54.

Bohne, A., Lang, E., and von der Lieth, C.-W. 1998. W3-SWEET: Carbohydrate modeling by Internet. J. Mol. Model. 4:33-43.

Bohne, A., Lang, E., and von der Lieth, C. W. 1999. SWEET-WWWbased rapid 3D construction of oligo- and polysaccharides. Bioinformatics 15:767-768

Boller, T., and Felix, G. 2009. A renaissance of elicitors: Perception of microbe-associated molecular patterns and danger signals by patternrecognition receptors. Annu. Rev. Plant Biol. 60:379-406.

Bolton, M. D., van Esse, H. P., Vossen, J. H., de Jonge, R., Stergiopoulos, I., Stulemeijer, I. J. E., van den Berg, G. C. M., Borrás-Hidalgo, O., Dekker, H. L., de Koster, C. G., de Wit, P. J. G. M., Joosten, M. H. A. J., and Thomma, B. P. H. J. 2008. The novel Cladosporium fulvum lysin motif effector Ecp6 is a virulence factor with orthologues in other fungal species. Mol. Microbiol. 69:119-136.

Cao, Y., Liang, Y., Tanaka, K., Nguyen, C. T., Jedrzejczak, R. P. Joachimiak, A., and Stacey, G. 2014. The kinase LYK5 is a major chitin receptor in Arabidopsis and forms a chitin-induced complex with related kinase CERK1. eLife 3:e03766.

Cregeen, S., Radišek, S., Mandelc, S., Turk, B., Štajner, N., Jakše, J., and Javornik, B. 2015. Different gene expressions of resistant and susceptible hop cultivars in response to infection with a highly aggressive strain of Verticillium albo-atrum. Plant Mol. Biol. Rep. 33:689-704.

Dawson, N. L., Sillitoe, I., Lees, J. G., Lam, S. D., and Orengo, C. A. 2017. CATH-Gene3D: Generation of the resource and its use in obtaining structural and functional annotations for protein sequences. Pages 79-110 in: Protein Bioinformatics. Methods in Molecular Biology, Vol. 1558. C. Wu, C. Arighi, and K. Ross, eds. Humana Press, New York, NY, U.S.A.

de Jonge, R., and Thomma, B. P. H. J. 2009. Fungal LysM effectors: Extinguishers of host immunity? Trends Microbiol. 17:151-157.

de Jonge, R., van Esse, H. P., Kombrink, A., Shinya, T., Desaki, Y., Bours, R., van der Krol, S., Shibuya, N., Joosten, M. H. A. J., and Thomma, B. P. H. J. 2010. Conserved fungal LysM effector Ecp6 prevents chitintriggered immunity in plants. Science 329:953-955.

Dodds, P. N., and Rathjen, J. P. 2010. Plant immunity: Towards an integrated view of plant-pathogen interactions. Nat. Rev. Genet. 11:539-548.

Duan, Y., Wu, C., Chowdhury, S., Lee, M. C., Xiong, G., Zhang, W., Yang, R., Cieplak, P., Luo, R., Lee, T., Caldwell, J., Wang, J., and Kollman, P. 2003. A point-charge force field for molecular mechanics simulations of proteins based on condensed-phase quantum mechanical calculations. J. Comput. Chem. 24:1999-2012.

Finn, R. D., Bateman, A., Clements, J., Coggill, P., Eberhardt, R. Y., Eddy, S. R., Heger, A., Hetherington, K., Holm, L., Mistry, J., Sonnhammer, E. L. L., Tate, J., and Punta, M. 2014. Pfam: The protein families database. Nucleic Acids Res. 42 D222-D230.

Flajšman, M., Mandelc, S., Radišek, S., and Javornik, B. 2018. Xylem sap extraction method from hop plants. Bio Protoc. 7:1-11.

Flajšman, M., Mandelc, S., Radišek, S., Štajner, N. N., Jakše, J., Košmelj, K., and Javornik, B. 2016. Identification of novel virulence-associated proteins secreted to xylem by Verticillium nonalfalfae during colonization of hop plants. Mol. Plant-Microbe Interact. 29:362-373.

Flajšman, M., Radišek, S., and Javornik, B. 2017. Pathogenicity assay of Verticillium nonalfalfae on hop plants. Bio Protoc. 7:1-10.

Gubaeva, E., Gubaev, A., Melcher, R. L. J., Cord-Landwehr, S., Singh, R., El Gueddari, N. E., and Moerschbacher, B. M. 2018. 'Slipped sandwich' model for chitin and chitosan perception in Arabidopsis. Mol. PlantMicrobe Interact. 31:1145-1153.

Guillén, D., Sánchez, S., and Rodríguez-Sanoja, R. 2010. Carbohydratebinding domains: Multiplicity of biological roles. Appl. Microbiol Biotechnol. 85:1241-1249.

Gust, A. A., Willmann, R., Desaki, Y., Grabherr, H. M., and Nürnberger, T. 2012. Plant LysM proteins: Modules mediating symbiosis and immunity. Trends Plant Sci. 17:495-502. 
Hayafune, M., Berisio, R., Marchetti, R., Silipo, A., Kayama, M., Desaki, Y., Arima, S., Squeglia, F., Ruggiero, A., Tokuyasu, K., Molinaro, A., Kaku, H., and Shibuya, N. 2014. Chitin-induced activation of immune signaling by the rice receptor $\mathrm{CEBiP}$ relies on a unique sandwich-type dimerization. Proc. Natl. Acad. Sci. U.S.A. 111:E404-E413.

Hurlburt, N. K., Chen, L.-H., Stergiopoulos, I., and Fisher, A. J. 2018. Structure of the Cladosporium fulvum Avr4 effector in complex with (GlcNAc) ${ }_{6}$ reveals the ligand-binding mechanism and uncouples its intrinsic function from recognition by the $\mathrm{Cf}-4$ resistance protein. PLoS Pathog. 14:e1007263.

Jakše, J., Čerenak, A., Radišek, S., Satovic, Z., Luthar, Z., and Javornik, B. 2013. Identification of quantitative trait loci for resistance to Verticillium wilt and yield parameters in hop (Humulus lupulus L.). Theor. Appl. Genet. 126:1431-1443.

Jakše, J., Jelen, V., Radišek, S., de Jonge, R., Mandelc, S., Majer, A., Curk, T., Zupan, B., Thomma, B. P. H. J., and Javornik, B. 2018. Genome sequence of a lethal strain of xylem-invading Verticillium nonalfalfae. Genome Announce. 6:e01458-17.

Jiménez-Barbero, J., Javier Cañada, F., Asensio, J. L., Aboitiz, N., Vidal, P., Canales, A., Groves, P., Gabius, H.-J., and Siebert, H.-C. 2006. Hevein domains: An attractive model to study carbohydrate-protein interactions at atomic resolution. Adv. Carbohydr. Chem. Biochem. 60:303-354.

Jones, J. D. G. G., and Dangl, J. L. 2006. The plant immune system. Nature 444:323-329.

Kastritis, P. L., and Bonvin, A. M. J. J. 2013. On the binding affinity of macromolecular interactions: Daring to ask why proteins interact. J. R. Soc. Interface 10:20120835.

Kombrink, A., Rovenich, H., Shi-Kunne, X., Rojas-Padilla, E., van den Berg, G. C. M., Domazakis, E., de Jonge, R., Valkenburg, D. J., SánchezVallet, A., Seidl, M. F., and Thomma, B. P. H. J. 2017. Verticillium dahliae LysM effectors differentially contribute to virulence on plant hosts. Mol. Plant Pathol. 18:596-608.

Krieger, E., and Vriend, G. 2014. YASARA View-Molecular graphics for all devices-From smartphones to workstations. Bioinformatics 30: 2981-2982.

Krieger, E., and Vriend, G. 2015. New ways to boost molecular dynamics simulations. J. Comput. Chem. 36:996-1007.

Langezaal, C. R., and Scheffer, J. J. C. 1992. Initiation and growth characterization of some hop cell suspension cultures. Plant Cell Tissue Organ Cult. 30:159-164.

Lerner, D. R., and Raikhel, N. V. 1992. The gene for stinging nettle lectin (Urtica dioica agglutinin) encodes both a lectin and a chitinase. J. Biol. Chem. 267:11085-11091.

Li, W., Cowley, A., Uludag, M., Gur, T., McWilliam, H., Squizzato, S., Park, Y. M., Buso, N., and Lopez, R. 2015. The EMBL-EBI bioinformatics web and programmatic tools framework. Nucleic Acids Res. 43:W580-W584.

Liu, P., and Stajich, J. E. 2015. Characterization of the carbohydrate binding module 18 gene family in the amphibian pathogen Batrachochytrium dendrobatidis. Fungal Genet. Biol. 77:31-39.

Liu, S., Wang, J., Han, Z., Gong, X., Zhang, H., and Chai, J. 2016. Molecular mechanism for fungal cell wall recognition by rice chitin receptor OsCEBiP. Structure 24:1192-1200.

Liu, T., Liu, Z., Song, C., Hu, Y., Han, Z., She, J., Fan, F., Wang, J., Jin, C., Chang, J., Zhou, J. M., and Chai, J. 2012. Chitin-induced dimerization activates a plant immune receptor. Science 336:1160-1164.

Liu, W., Xie, Y., Ma, J., Luo, X., Nie, P., Zuo, Z., Lahrmann, U., Zhao, Q., Zheng, Y., Zhao, Y., Xue, Y., and Ren, J. 2015. IBS: An illustrator for the presentation and visualization of biological sequences. Bioinformatics 31:3359-3361.

Lombard, V., Golaconda Ramulu, H., Drula, E., Coutinho, P. M., and Henrissat, B. 2014. The carbohydrate-active enzymes database (CAZy) in 2013. Nucleic Acids Res. 42:D490-D495.

Macho, A. P., and Zipfel, C. 2014. Plant PRRs and the activation of innate immune signaling. Mol. Cell 54:263-272.

Mandelc, S., and Javornik, B. 2015. The secretome of vascular wilt pathogen Verticillium albo-atrum in simulated xylem fluid. Proteomics 15:787-797.

Marshall, R., Kombrink, A., Motteram, J., Loza-Reyes, E., Lucas, J., Hammond-Kosack, K. E., Thomma, B. P. H. J., and Rudd, J. J. 2011. Analysis of two in planta expressed LysM effector homologs from the fungus Mycosphaerella graminicola reveals novel functional properties and varying contributions to virulence on wheat. Plant Physiol. 156: 756-769.

Marton, K., Flajšman, M., Radišek, S., Košmelj, K., Jakše, J., Javornik, B., and Berne, S. 2018. Comprehensive analysis of Verticillium nonalfalfae in silico secretome uncovers putative effector proteins expressed during hop invasion. PLoS One 13:e0198971.
Mentlak, T. A., Kombrink, A., Shinya, T., Ryder, L. S., Otomo, I., Saitoh, H., Terauchi, R., Nishizawa, Y., Shibuya, N., Thomma, B. P. H. J., and Talbot, N. J. 2012. Effector-mediated suppression of chitin-triggered immunity by Magnaporthe oryzae is necessary for rice blast disease. Plant Cell 24:322-335.

Miya, A., Albert, P., Shinya, T., Desaki, Y., Ichimura, K., Shirasu, K., Narusaka, Y., Kawakami, N., Kaku, H., and Shibuya, N. 2007. CERK1, a LysM receptor kinase, is essential for chitin elicitor signaling in Arabidopsis. Proc. Natl. Acad. Sci. U.S.A. 104:19613-19618.

Mochizuki, S., Saitoh, K.-I., Minami, E., and Nishizawa, Y. 2011. Localization of probe-accessible chitin and characterization of genes encoding chitin-binding domains during rice-Magnaporthe oryzae interactions. J. Gen. Plant Pathol. 77:163-173.

Möller, E. M. M., Bahnweg, G., Sandermann, H., and Geiger, H. H. H. 1992. A simple and efficient protocol for isolation of high molecular weight DNA from filamentous fungi, fruit bodies, and infected plant tissues. Nucleic Acids Res. 20:6115-6116.

Progar, V., Jakše, J., Štajner, N., Radišek, S., Javornik, B., and Berne, S. 2017. Comparative transcriptional analysis of hop responses to infection with Verticillium nonalfalfae. Plant Cell Rep. 36:1599-1613.

Punja, Z. K., and Zhang, Y.-Y. 1993. Plant chitinases and their roles in resistance to fungal diseases. J. Nematol. 25:526-540.

Pusztahelyi, T. 2018. Chitin and chitin-related compounds in plant-fungal interactions. Mycology 9:189-201.

Qi, X., Sun, Y., and Xiong, S. 2015. A single freeze-thawing cycle for highly efficient solubilization of inclusion body proteins and its refolding into bioactive form. Microb. Cell Fact. 14:24.

Radišek, S., Jakše, J., and Javornik, B. 2004. Development of pathotypespecific SCAR markers for detection of Verticillium albo-atrum isolates from hop. Plant Dis. 88:1115-1122.

Radišek, S., Jakše, J., and Javornik, B. 2006. Genetic variability and virulence among Verticillium albo-atrum isolates from hop. Eur. J. Plant Pathol. 116:301-314.

Radišek, S., Jakše, J., Simončič, A., and Javornik, B. 2003. Characterization of Verticillium albo-atrum field isolates using pathogenicity data and AFLP analysis. Plant Dis. 87:633-638.

Ranf, S. 2017. Sensing of molecular patterns through cell surface immune receptors. Curr. Opin. Plant Biol. 38:68-77.

R Core Team. 2016. R: A Language and Environment for Statistical Computing. R Foundation for Statistical Computing, Vienna, Austria.

Sánchez-Vallet, A., Mesters, J. R., and Thomma, B. P. H. J. 2015. The battle for chitin recognition in plant-microbe interactions. FEMS Microbiol. Rev. 39:171-183.

Sánchez-Vallet, A., Saleem-Batcha, R., Kombrink, A., Hansen, G., Valkenburg, D.-J. J., Thomma, B. P. H. J., and Mesters, J. R. 2013. Fungal effector Ecp6 outcompetes host immune receptor for chitin binding through intrachain LysM dimerization. eLife 2:e00790.

Schmittgen, T. D., and Livak, K. J. 2008. Analyzing real-time PCR data by the comparative C(T) method. Nat. Protoc. 3:1101-1108.

Seidl, M. F., Faino, L., Shi-Kunne, X., van den Berg, G. C. M., Bolton, M. D., and Thomma, B. P. H. J. 2015. The genome of the saprophytic fungus Verticillium tricorpus reveals a complex effector repertoire resembling that of its pathogenic relatives. Mol. Plant-Microbe Interact. 28:362-373.

Shibuya, N., and Minami, E. 2001. Oligosaccharide signalling for defence responses in plant. Physiol. Mol. Plant Pathol. 59:223-233.

Shimizu, T., Nakano, T., Takamizawa, D., Desaki, Y., Ishii-Minami, N., Nishizawa, Y., Minami, E., Okada, K., Yamane, H., Kaku, H., and Shibuya, N. 2010. Two LysM receptor molecules, CEBiP and OsCERK1, cooperatively regulate chitin elicitor signaling in rice. Plant J. 64:204-214.

Shinya, T., Nakagawa, T., Kaku, H., and Shibuya, N. 2015. Chitin-mediated plant-fungal interactions: Catching, hiding and handshaking. Curr. Opin. Plant Biol. 26:64-71.

Signorell, A. 2017. DescTools v0.99.19. https://www.rdocumentation.org/ packages/DescTools/versions/0.99.19

Soanes, D. M., Alam, I., Cornell, M., Wong, H. M., Hedeler, C., Paton, N. W., Rattray, M., Hubbard, S. J., Oliver, S. G., and Talbot, N. J. 2008 Comparative genome analysis of filamentous fungi reveals gene family expansions associated with fungal pathogenesis. PLoS One 3:e2300.

Sperschneider, J., Dodds, P. N., Singh, K. B., and Taylor, J. M. 2018. ApoplastP: Prediction of effectors and plant proteins in the apoplast using machine learning. New Phytol. 217:1764-1778.

Štajner, N., Cregeen, S., and Javornik, B. 2013. Evaluation of reference genes for RT-qPCR expression studies in hop (Humulus lupulus L.) during infection with vascular pathogen Verticillium albo-atrum. PLoS One 8:e68228.

Stergiopoulos, I., De Kock, M. J. D., Lindhout, P., and De Wit, P. J. G. M. 2007. Allelic variation in the effector genes of the tomato pathogen 
Cladosporium fulvum reveals different modes of adaptive evolution. Mol. Plant-Microbe Interact. 20:1271-1283.

Stergiopoulos, I., van den Burg, H. A., Okmen, B., Beenen, H. G., van Liere, S., Kema, G. H. J., and de Wit, P. J. G. M. 2010. Tomato Cf resistance proteins mediate recognition of cognate homologous effectors from fungi pathogenic on dicots and monocots. Proc. Natl. Acad. Sci. U.S.A. 107:7610-7615

Takahara, H., Hacquard, S., Kombrink, A., Hughes, H. B., Halder, V., Robin, G. P., Hiruma, K., Neumann, U., Shinya, T., Kombrink, E., Shibuya, N., Thomma, B. P. H. J., and O'Connell, R. J. 2016. Colletotrichum higginsianum extracellular LysM proteins play dual roles in appressorial function and suppression of chitin-triggered plant immunity. New Phytol. 211:1323-1337.

Trott, O., and Olson, A. J. 2010. AutoDock Vina: Improving the speed and accuracy of docking with a new scoring function, efficient optimization, and multithreading. J. Comput. Chem. 31:455-461.

van den Burg, H. A., Harrison, S. J., Joosten, M. H. A. J., Vervoort, J., and de Wit, P. J. G. M. 2006. Cladosporium fulvum Avr4 protects fungal cell walls against hydrolysis by plant chitinases accumulating during infection. Mol. Plant-Microbe Interact. 19:1420-1430. van den Burg, H. A., Spronk, C. A. E. M., Boeren, S., Kennedy, M. A. Vissers, J. P. C., Vuister, G. W., de Wit, P. J. G. M., and Vervoort, J. 2004. Binding of the AVR4 elicitor of Cladosporium fulvum to chitotriose units is facilitated by positive allosteric protein-protein interactions: The chitin-binding site of AVR4 represents a novel binding site on the folding scaffold shared between the invertebrate and the plant chitin-binding domain. J. Biol. Chem. 279:16786-16796.

van Esse, H. P., Bolton, M. D., Stergiopoulos, I., de Wit, P. J. G. M., and Thomma, B. P. H. J. 2007. The chitin-binding Cladosporium fulvum effector protein Avr4 is a virulence factor. Mol. Plant-Microbe Interact. 20:1092-1101.

Waterhouse, A., Bertoni, M., Bienert, S., Studer, G., Tauriello, G., Gumienny, R., Heer, F. T., de Beer, T. A. P., Rempfer, C., Bordoli, L., Lepore, R., and Schwede, T. 2018. SWISS-MODEL: Homology modelling of protein structures and complexes. Nucleic Acids Res. 46: W296-W303.

Wright, H. T., Sandrasegaram, G., and Wright, C. S. 1991. Evolution of a family of $\mathrm{N}$-acetylglucosamine binding proteins containing the disulfide-rich domain of wheat germ agglutinin. J. Mol. Evol. 33: 283-294. 